\title{
Recent Development of Graphene-Based Ink and Other Conductive Material-Based Inks for Flexible Electronics
}

\author{
D.S. SAIDINA, ${ }^{1,2}$ N. EAWWIBOONTHANAKIT, ${ }^{1}$ M. MARIATTI $\mathbb{C}^{1,3}$ \\ S. FONTANA, ${ }^{2}$ and C. HÉROLD ${ }^{2}$ \\ 1.-School of Materials and Mineral Resources Engineering, Engineering Campus, Universiti \\ Sains Malaysia, 14300 Nibong Tebal, Penang, Malaysia. 2.-Institut Jean Lamour, Campus \\ Artem, 2 Allée André Guinier, BP 50840, 54011 Nancy Cedex, France. 3.-e-mail: \\ mariatti@usm.my
}

The promising and extraordinary properties of graphene have attracted significant interest, making graphene an alternative to replace many traditional materials for many applications, particularly in conductive ink for the fabrication of flexible electronics. For the past 10 years, numerous studies have been reported on the synthesis of graphene conductive ink for printing on flexible substrates for various electronic applications. The development of graphene-based ink is reviewed, with the main focus on the types of graphenelike materials in conductive inks, and the compositions and important properties of those inks. Another intention behind this review is to compare the pros and cons of graphene-based ink with those using other common conductive materials, such as gold nanoparticles, silver nanoparticles, copper nanoparticles, conductive polymers and carbon nanotubes. Recent works on graphene hybrid-based ink containing other metallic nanoparticles as an alternative way to improve the electrical properties of the conductive inks are also reported. Brief comparisons between inkjet printing and other printing techniques for the fabrication of flexible electronics are discussed.

Key words: Conductive inks, graphene, graphene-based ink, graphene hybrid-based ink, flexible electronics, inkjet printing

\section{INTRODUCTION}

Recent years have witnessed a revolution in graphene due to its distinctive physicochemical properties, tremendous mechanical performance and its unique electrical and thermal conductivities. ${ }^{1}$ Presently, graphene is widely used in various electronic applications including as conductive inks for printable flexible electronics. The expression 'graphene' consists of a prefix of 'graph' from graphite and suffix 'ene' from $\mathrm{C}-\mathrm{C}$ double bonds. ${ }^{2,3}$ Graphene by definition is a single atomic layer of carbon atoms packed into a two-dimensional (2D) honeycomb lattice structure. The atoms are arranged in a hexagonal structure creating a sheet

(Received November 22, 2018; accepted March 29, 2019;

published online April 8, 2019) of $s p^{2}$ tightly bonded carbon. Graphene has been considered as 'the thinnest, most flexible and strongest material known' that conducts heat and electricity very well. ${ }^{4,5}$ The $2 \mathrm{D}$ carbon thickness is from $0.34 \mathrm{~nm}$ (monolayer graphene) up to micrometres. In 1947, Wallace ${ }^{6}$ explained that almost all 'graphene-like materials' are different from the idealised 2D 'graphene structure'. Several types of graphene-like materials had existed, from monolayer to multilayer graphene, turbostratic carbon, graphite nanoplatelets (GNPs), nanosheets, nanoflakes and graphene oxide (GO).

To date, several methods for the production of graphene have been explored, and these methods are divided into two categories: (1) bottom-up approach (from carbon precursors), i.e. synthesis on silicon carbide, chemical vapour deposition, solvothermal reaction, etc., and (2) top-down approach (from graphite), i.e. micromechanical 
cleavage, liquid phase exfoliation, chemical reduction of GO and exfoliation of graphite intercalation compounds, etc. The bottom-up approaches can produce graphene with fewer defects; however, these methods suffer from high complexity, low yield and the high cost of metal substrates. Meanwhile, top-down approaches produce graphene in high yield, use solution-based processability and are easy to implement due to the use of the existing form of a bulk material. ${ }^{7-11}$

Much research into conductive nanomaterials and conductive polymer inks for the production of printed electronic applications has been carried out. Among them, metal-based inks such as those containing gold nanoparticles (AuNPs), silver nanoparticles (AgNPs) and copper nanoparticles (CuNPs) have received great attention due to their excellent electrical conductivity. However, AuNPs and AgNPs suffer from high cost and require high sintering temperatures, which limit their functions for use with flexible substrates, ${ }^{12-14}$ and makes CuNPs a good alternative due to their low cost and high electrical conductivity. However, CuNPs have issues with oxidation under heat and humid conditions, which limit their applications. ${ }^{15}$ Meanwhile the electrical conductivity of conductive polymers is still considered to be very low compared to those of metal-based inks. ${ }^{16}$ Due to that, and considering the advantages of graphene over other conductive nanoparticles and conductive polymers, graphenebased inks have been widely explored over the past 10 years; however, more effort is still needed before they can be used in practical applications. Extensive work to produce large-scale, high-quality, low-cost and eco-friendly techniques for graphene-based inks is still necessary. Ink formulation and properties mainly influence the printing quality and must be optimised in order to achieve patterns without a coffee ring effect, and to produce homogeneity in the printed patterns.

Various printing techniques, including screen printing, spray coating, 3D printing, inkjet printing, etc., have been utilised in the fabrication of conductive ink patterns for flexible electronic applications. ${ }^{17}$ Among these printing techniques, inkjet printing has received the most attention, due to the simple printing process, high repeatability, economy and time-saving compared to other printing techniques. However, inkjet printing often suffers from nozzle clogging due to aggregation of the particles in the conductive inks. Thus, ink properties such as viscosity, surface tension, etc. should be optimised in order to meet the specific printing requirements. Hoath ${ }^{18}$ reported that an ideal ink should possess low viscosity and high surface tension in order to flow through the nozzle easily without coagulation or obstruction of the nozzle.

Yang and Wang ${ }^{19}$ in their previous review paper emphasised the development of graphene and graphene hybrid inks by focusing on ink formulations, properties and applications. Therefore, this review is aimed at comparing the electrical properties, advantages, issues and recent developments of graphene, other conductive materials and graphene hybrid inks for flexible electronic applications. Besides that, details of the conductive ink compositions and physical properties, such as viscosity and surface tension, are discussed thoroughly. Various printing techniques, mainly inkjet printing and other printing techniques for the production of conductive ink patterns are compared, with reference to their advantages and drawbacks and the details of drop-on-demand inkjet printing.

\section{CONDUCTIVE INK MATERIALS}

A conductive ink is a thermoplastic viscous paste that conducts electricity by inculcating conductive materials. ${ }^{20}$ The traditional function of conductive ink is to create conductive paths for use as interconnects. ${ }^{21}$ To be specific, the conductive inks are suspensions of conductive nanomaterials either in water or a solvent medium with addition of a surfactant or polymer that acts as a stabiliser. These solvents must evaporate rapidly after deposition, but not dry out quickly at the printhead nozzles while idle for short periods of time. To obtain high electrical conductivity of conductive inks, conductive nanomaterials are normally introduced; the sizes of these nanomaterials should be less than hundreds of nozzle sizes to avoid clogging the print head. An ideal conductive ink should be inexpensive, simple to prepare and offer good printability, low viscosity, good stability, good adhesion to the substrate, high electrical conductivity after printing and post-printing processing, and dry in a preferentially densified manner at a substrate surface without a coffee ring effect. ${ }^{22-24}$

Conductive ink becomes an important element in printing industry, in such processes as inkjet printing, screen printing, gravure printing, flexographic printing and roll-to-roll printing. Figure 1 shows the number of papers published in the field of

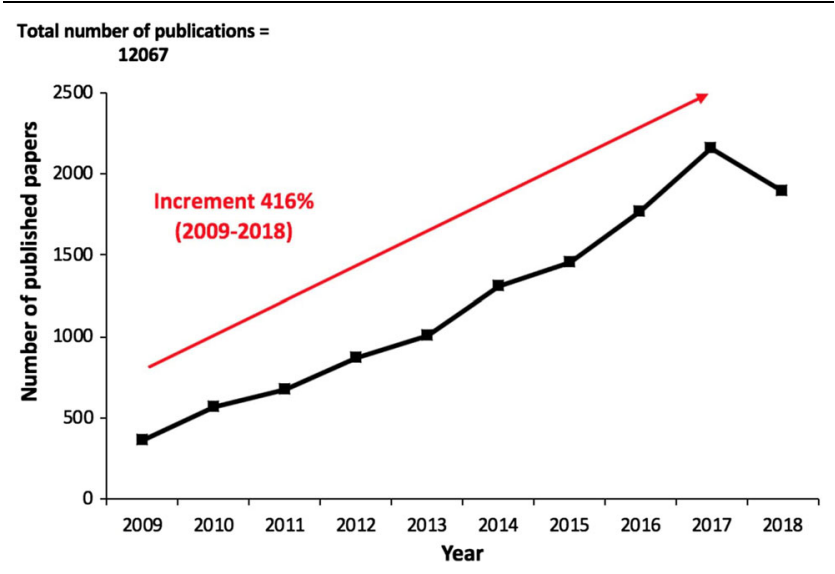

Fig. 1. The number of published papers for conductive inks 20092018 from Scopus and Web of Science by searching for the topic "conductive ink" (data acquired on October 2018). 
conductive inks; note that the statistics were taken from Scopus and Web of Science. The number of published papers on conductive inks are increasing continuously, specifically in the last few years in accordance with an increase in market value share. The number has increased sharply from about 366 articles in 2009 to more than 1890 in 2018. Figure 2 illustrates the market value share for conductive inks in emerging sectors. Conductive inks are widely used in printed electronic applications, including organic light-emitting diodes (OLEDs), organic and inorganic photovoltaics, flexible displays, radio-frequency identification (RFID) and healthcare devices, thin-film transistors, solar cells, sensors, smart textiles, batteries, memory components and antennas. ${ }^{25-29}$ The market value share for conductive inks is expected to increase gradually up to 2026.

\section{Graphene-Based Ink}

Carbon nanomaterials offer numerous possibilities for printed and flexible electronics. Due to its promising and extraordinary properties, graphene has been widely used in the fabrication of printed electronics. Graphene conductive inks have the potential to revolutionise the printed conductor field by replacing metallic inks, conductive polymer inks and other carbon material inks, while at the same time reducing biological hazards and production costs. ${ }^{30}$

Huang et al. $^{31}$ reported that a series of inkjet printing processes using water-soluble single-layered GO and few-layered GO (FGO) have been printed on diverse flexible substrates. Based on these findings, the electrical conductivity of GO and FGO after 25 printed layers on a polyimide (PI)

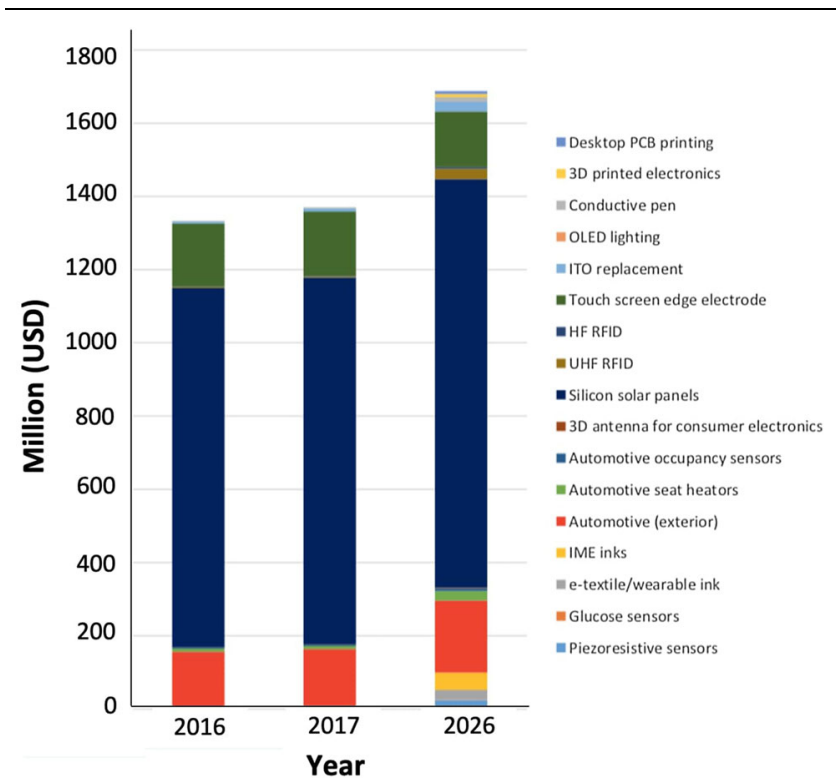

Fig. 2. Market value share (million USD) for conductive inks in emerging sectors 2016-2026 (reproduced with permission from IDTechEx Research, 2016). ${ }^{25}$ substrate are $5.0 \times 10^{2} \mathrm{~S} / \mathrm{m}$ and $9.0 \times 10^{2} \mathrm{~S} / \mathrm{m}$, respectively. According to Huang et al., the low conductivity of GO printed on PI compared to FGO could be attributed to the high number of oxygencontaining groups in the GO sample (Fig. 3). In 2017, Pei and $\mathrm{Li}^{32}$ fabricated GO ink by dispersing GO in mixed solvents of deionised water, ethanol and ethylene glycol in the ratio of 1:1:1 using ultrasonication. The prepared ink was inkjetprinted onto a poly(ethylene terephthalate) (PET) substrate and the electrical conductivity after 20 printed layers was $0.497 \mathrm{~S} / \mathrm{m}$. They also investigated the electrical properties of treated and untreated PET using an oxygen-plasma treatment. The findings showed that electrical conductivity of the treated PET was significantly improved over that of untreated PET at the same number of printed layers.

Arapov et al. ${ }^{30}$ presented a comparison of two graphene inks: one prepared by the solubilisation of expanded graphite in the presence of a surfaceactive polymer, and the other by covalent graphene functionalisation followed by redispersion in a solvent but without a surfactant. Based on their findings, the conductivity levels for expanded graphite-based inks and functionalised graphene are approximately $1-2 \mathrm{k} \Omega / \mathrm{sq}$ and $2 \mathrm{M} \Omega / \mathrm{sq}$, respectively, for 15 printed layers. This technique is simple and efficient, and therefore has a potential to be used for large-area printing of conductive films. Meanwhile, Gao et al. ${ }^{33}$ fabricated highly conductive pristine graphene electrodes by inkjet printing using ethyl cellulose-stabilised ink prepared from pristine graphene. No graphene sheets were observed to settle at the bottom of the bottle even after 9 months. This stability is reported to be due to the strong hydrophobic interactions between ethyl cellulose (as the stabilising polymer) and the graphene sheets countering the van der Waals forces between the graphene flakes, thereby inhibiting the aggregation of the graphene. The printed films have high conductivity with the value of $9.24 \times 10^{3} \mathrm{~S} / \mathrm{m}$ after 30 printed layers annealed at $300^{\circ} \mathrm{C}$ for $30 \mathrm{~min}$.

In 2016, Miao et al. ${ }^{34}$ reported a facile method of inkjet printing of graphene nanoplatelets (GNPs) using an electrochemical process in an inorganic salt-based electrolyte without using stabiliser. The electrical conductivity of printed pristine GNP film improved from $44 \mathrm{~S} / \mathrm{m}$ to approximately $2.5 \times 10^{3} \mathrm{~S} / \mathrm{m}$ after 20 printed layers after a simple thermal treatment of annealing at $300^{\circ} \mathrm{C}$ for $1 \mathrm{~h}$ (Fig. 4). Besides that, Majee et al. ${ }^{35}$ reported an efficient inkjet printing of water-based pristine GNP ink by a shear-exfoliation process with the aid of bromine intercalation in aqueous media using a water-soluble cellulose stabiliser, i.e. (hydroxypropyl)methyl cellulose. The direct current (DC) conductivity was $1.4 \times 10^{3} \mathrm{~S} / \mathrm{m}$ when the printed GNP film was dried at $100^{\circ} \mathrm{C}$, and increased to about $3 \times 10^{4} \mathrm{~S} / \mathrm{m}$ after an additional treatment of 

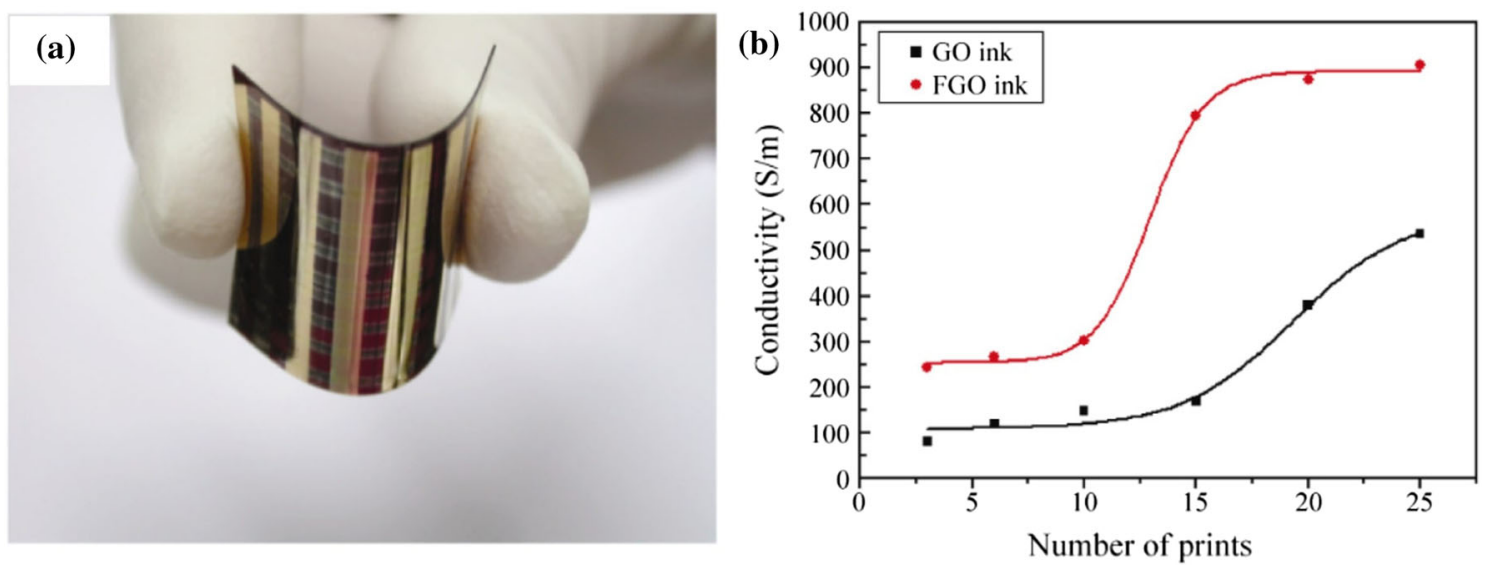

Fig. 3. (a) Photograph of a printed pattern on PI substrate bent outwards by nearly $75^{\circ}$ and (b) the electrical conductivity of the printed patterns on $\mathrm{PI}$ as a function of number of prints (reproduced with permission from Springer Nature, 2011). ${ }^{31}$

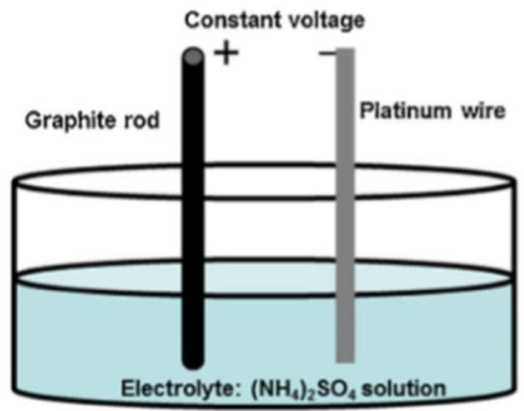

(a)

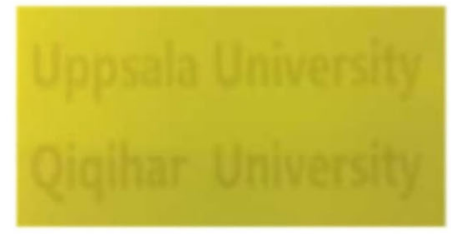

(c)

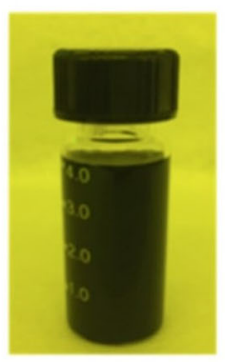

(b)

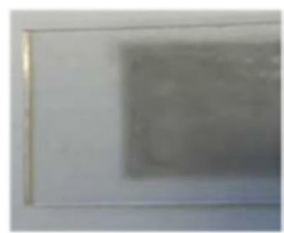

(d)

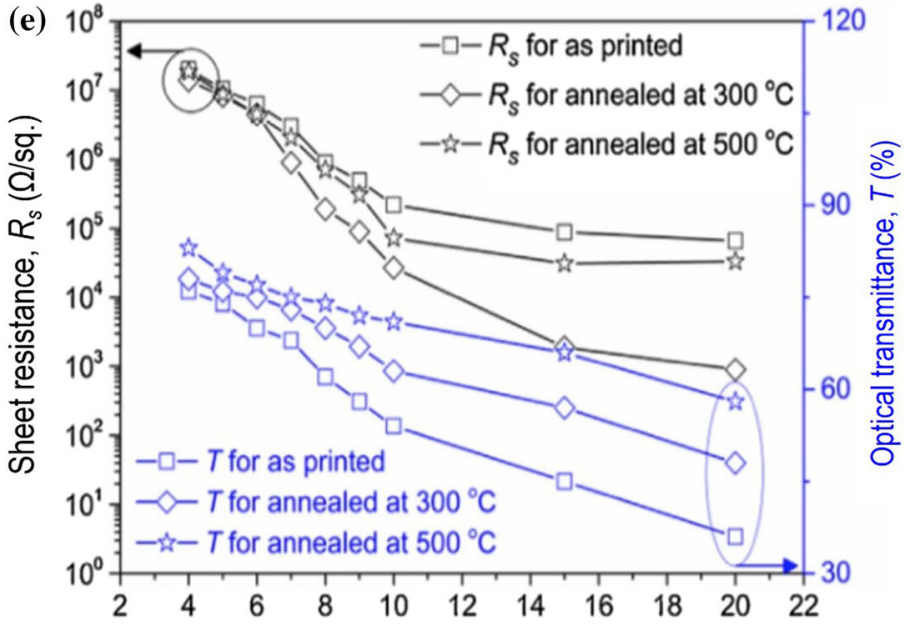

Number of printing cycle

Fig. 4. (a) Schematic experimental setup for the electrochemical exfoliation process, photo pictures of (b) electrochemical GNP ink ready for inkjet printing, (c) printed patterns on a plastic substrate, (d) printed test sample on a glass substrate, and (e) variations of sheet resistance and optical transmittance with number of printing cycles at different annealing temperatures (reproduced with permission from Elsevier, 2016). ${ }^{34}$

dipping the film in an aqueous iodine solution prior to drying. In contrast, a conductivity of about $2.4 \times 10^{4} \mathrm{~S} / \mathrm{m}$ was obtained after annealing the film at elevated temperature in air. The DC conductivity of the doped GNP films improved further to $10^{5} \mathrm{~S} / \mathrm{m}$ after annealing in air at $300^{\circ} \mathrm{C}$. This shows a positive effect of the combination of iodine doping and thermal annealing on conductivity enhancement for printed GNP films (Fig. 5).

Meanwhile, He and Derby ${ }^{36}$ fabricated reduced graphene oxide (rGO) film, printed on $\mathrm{Si} / \mathrm{SiO}_{2}$ and glass substrates, and dried at $80^{\circ} \mathrm{C}$. They managed to get high electrical conductivity, with a value of $1.53 \times 10^{4} \mathrm{~S} / \mathrm{m}$ to $2.48 \times 10^{4} \mathrm{~S} / \mathrm{m}$ with flake diameter increasing from $0.68 \mu \mathrm{m}$ to $35.9 \mu \mathrm{m}$. These findings showed that the electrical conductivity is comparable to that reported for printed pristine graphene films and rGO films, with values of $2.5 \times 10^{4} \mathrm{~S} / \mathrm{m}$ and $4.2 \times 10^{4} \mathrm{~S} / \mathrm{m}$, respectively. ${ }^{37-39}$ In 2017 , Secor et al. ${ }^{40}$ demonstrated graphene inks with nitrocellulose as a synergistic polymer stabiliser. The printed graphene films on glass had electrical conductivity values of $1.0 \times 10^{4} \mathrm{~S} / \mathrm{m}$ and $4.1 \times 10^{4} \mathrm{~S} / \mathrm{m}$ when annealed at $200^{\circ} \mathrm{C}$ and $350^{\circ} \mathrm{C}$, respectively.

Most of the graphene-based inks reported in the literature are prepared using GNPs, GO and rGO as filler. However, GNP has poor solubility in various types of common solvents due to the nature of graphene, which is hydrophobic. Because of that, the addition of a stabiliser or surfactant is required to improve the conductive ink dispersion. The main issue when using surfactant is the residual component in the final product, which has a negative effect 

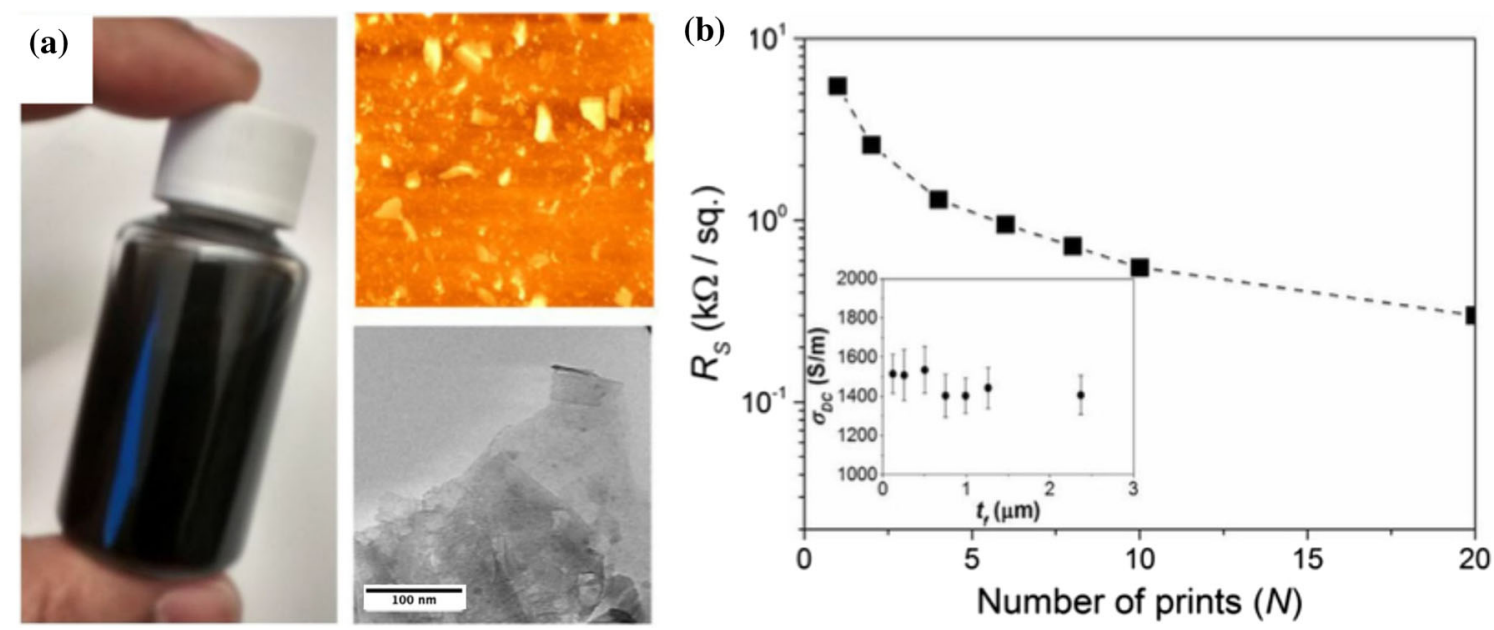

Fig. 5. (a) Photo of GNP ink (left), topographical AFM image of GNPs on $\mathrm{Si} / \mathrm{SiO}_{2}$ substrate (upper right) and HRTEM image of GNPS, and (b) sheet resistance with respect to number of prints (inset is the DC conductivity values as a function of thickness) (reproduced with permission from Elsevier, 2017). ${ }^{35}$

on the electrical properties of the printed pattern. It is important to remove surfactant from the printed pattern. Meanwhile, GO sheets suffer from low electrical conductivity due to the high content of oxygen-based functional groups. Therefore, a reduction process is required to remove the functional groups; however, the process involves highly toxic materials and introduces defects that compromise the conductivity value. Other than that, it is observed that printed graphene films exhibit high electrical conductivity values $\left(>10^{3} \mathrm{~S} / \mathrm{m}\right)$ after being annealed at high temperature; however, low annealing temperatures and short annealing duration are required in order to meet the requirements of printing processes on plastic substrates, and therefore for the fabrication of flexible electronic applications.

Table I presents a comparison of graphene-based inks and their electrical properties from the literature. ${ }^{26,30,31,33-35,38-40}$ It is observed that graphene inks based on various types of graphene-like materials have been successfully synthesised using sonication as the mixing method and inkjet printing as the fabrication method. Based on Table I, most of the graphene-based inks were prepared using GNPs, GO and rGO as filler. From the findings, we can observe that the number of printed layers, the annealing temperature and the type of substrate influences the electrical properties of the printed films. However, higher annealing temperature and longer annealing duration of printed graphene films restricts the used of polymer substrates for the fabrication of flexible printed electronics.

\section{Other Conductive Material-Based Ink}

\section{Ink Based on Conductive Nanomaterials}

Other than graphene, several types of commonly used conductive materials are also reported in the literature. Gold nanoparticles (AuNPs) are known as the most stable metal nanoparticles and have been used in printing highly conductive elements. The unique properties of AuNPs make them useful in various applications, such as colourants, metal coatings, electronics, optics and chemical catalysis. ${ }^{41}$ However, the high cost of AuNPs for mass production has overshadowed their merits in electronic applications. Besides that, they require high sintering temperature and long sintering time. Cui et al. ${ }^{12}$ reported that an AuNP ink protected by two overlapped layers of poly ( $N$-vinylpyrrolidone) (PVP) and acrylic resin (AR) exhibited a conductivity of $0.8 \times 10^{5} \mathrm{~S} / \mathrm{cm}$ with 50 printed layers sintered at $500^{\circ} \mathrm{C}$ for $3 \mathrm{~h}$ (Fig. 6). Meanwhile, Schoner et al. ${ }^{42}$ reported that gold structures printed on a glass substrate sintered at $280^{\circ} \mathrm{C}$ for $10 \mathrm{~min}$ were produced with a conductivity of $1.9 \times 10^{7} \mathrm{~S} / \mathrm{m}$. Printability was demonstrated for square structures and lines with an average width of $260 \mu \mathrm{m}$ and parallel edges.

Silver nanoparticles (AgNPs) are another promising nanomaterial for flexible electronics. Until now, AgNP-based inks have represented the most important commercial nanotechnology-derived product and the one most widely studied worldwide, other than graphene. ${ }^{43}$ However, the main issue with AgNPs is that the printed film has to be sintered at elevated temperature to achieve excellent conductivity. Previous researchers have realised that sintering temperatures above $200^{\circ} \mathrm{C}$ are not compatible with flexible polymer substrates such as PEN and PET due to their low glass-transition temperatures. ${ }^{44,45}$

Nie et al. ${ }^{13}$ reported the direct synthesis of a silver conductive film on a PET substrate by inkjet printing silver citrate conductive ink. The film reached a low resistivity of $17 \mu \Omega \mathrm{cm}$ after curing at $150^{\circ} \mathrm{C}$ for $50 \mathrm{~min}$ and $3.1 \mu \Omega \mathrm{cm}$ after curing at $230^{\circ} \mathrm{C}$ for $50 \mathrm{~min}$. This demonstrated that the curing conditions affect the Ag film and the RFID 
离|
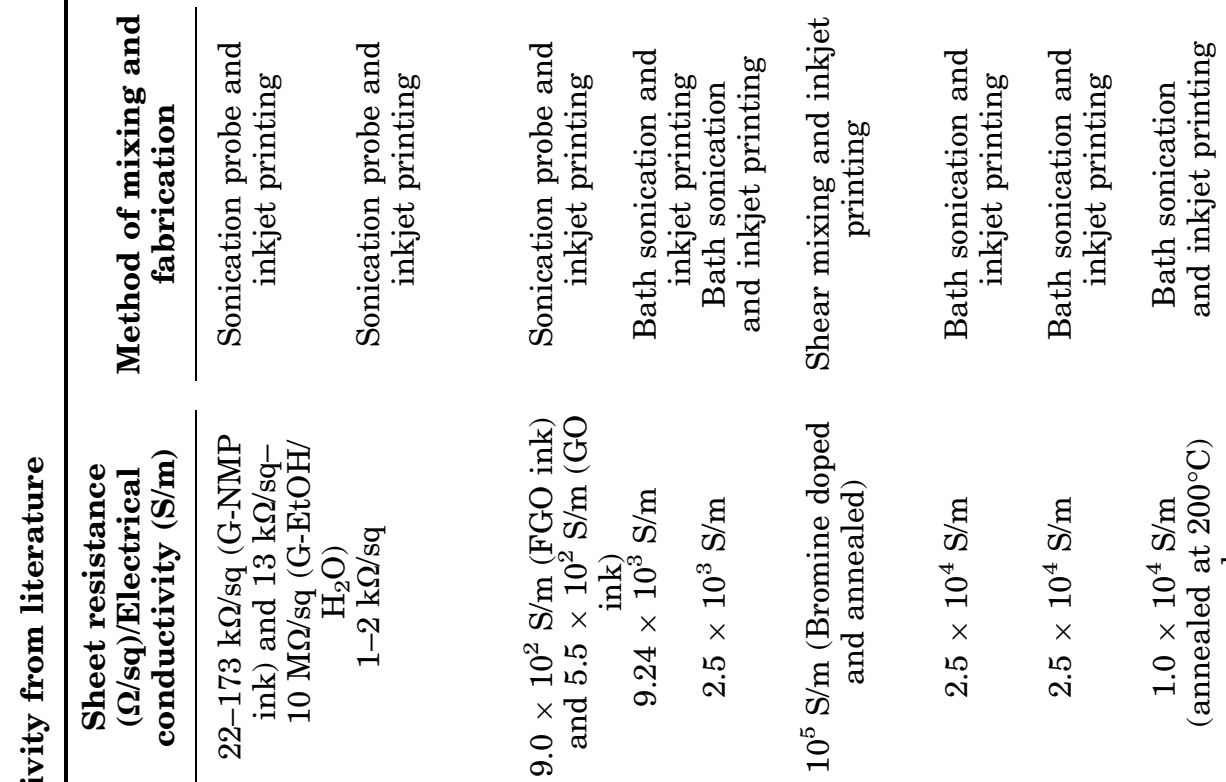

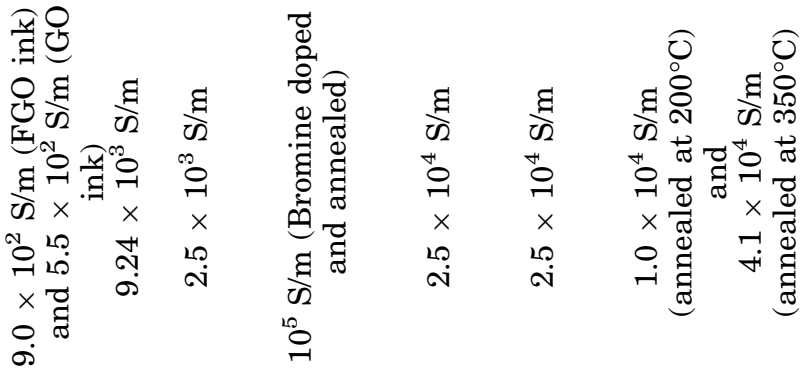

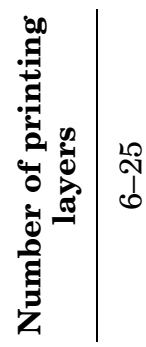

2

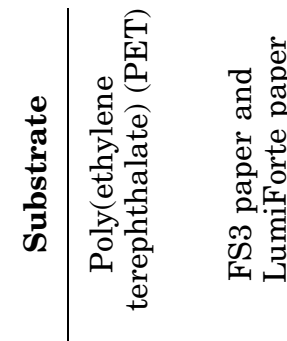

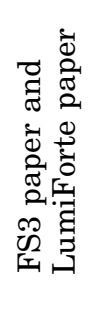

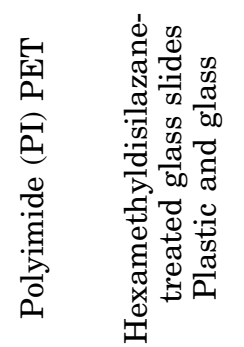
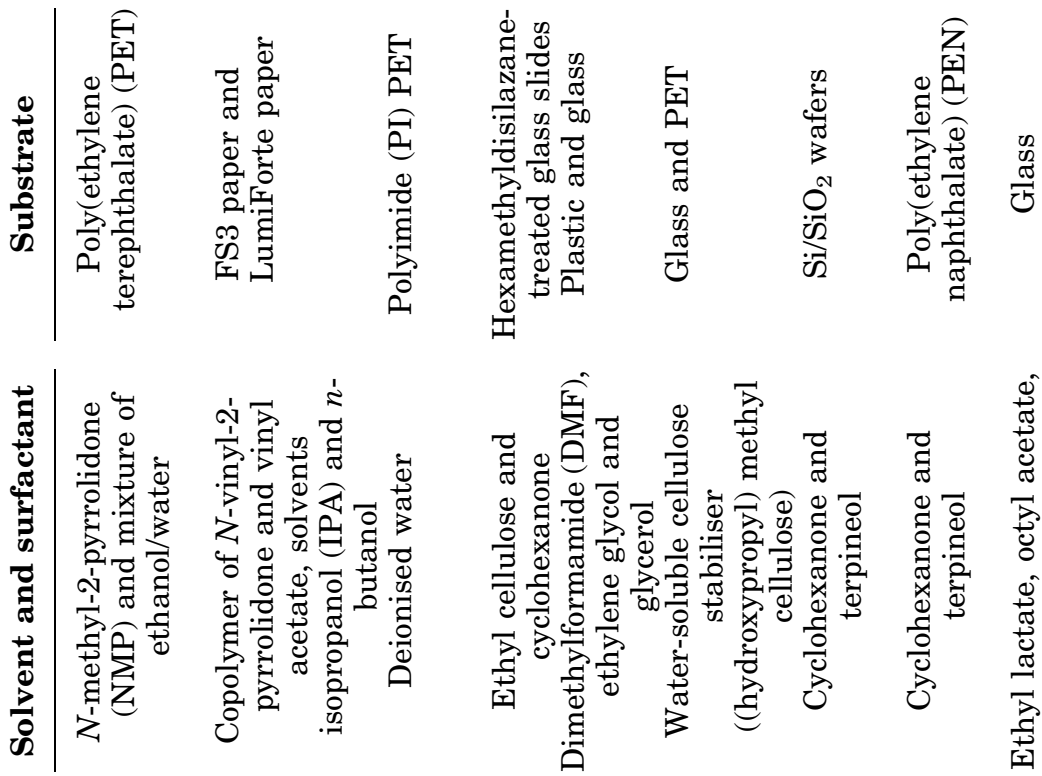

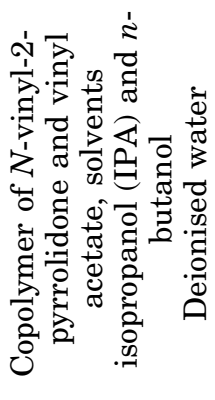

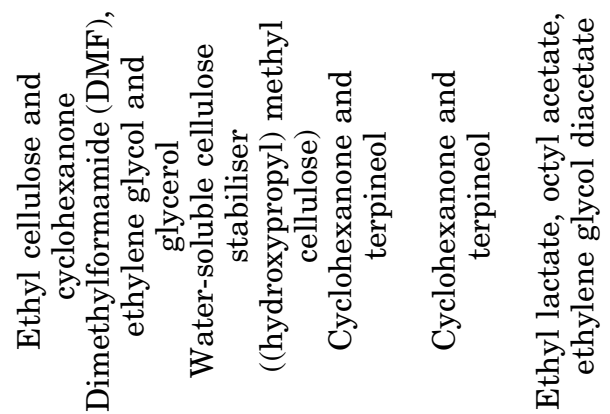
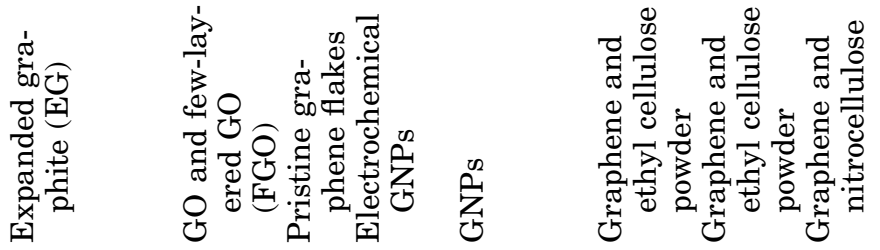
(a)

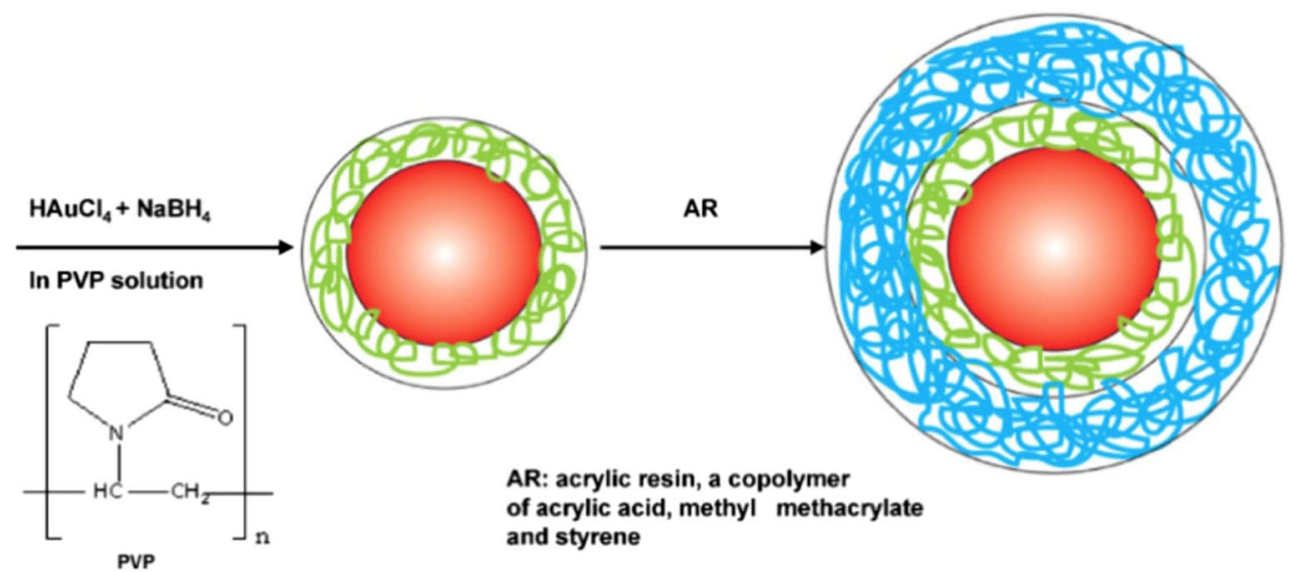

(b)

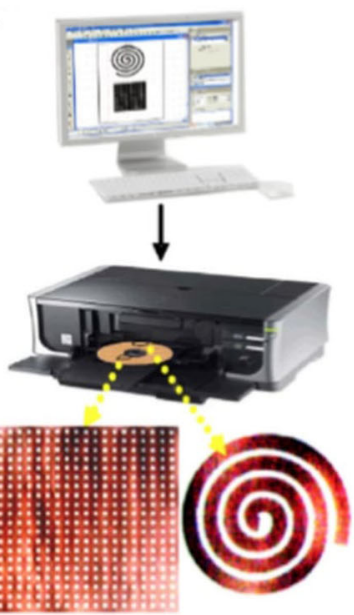

Fig. 6. Schematic (a) drawing showing the procedure of AuNP ink preparation and (b) diagram of the printing procedure for AuNP ink and the sample patterns printed on the paper and projection film (reproduced with permission from Elsevier, 2010). ${ }^{12}$

(a)
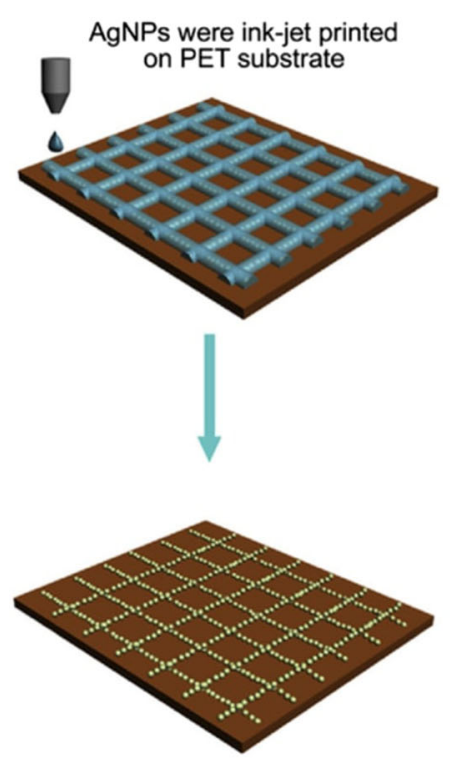

AgNPs assembly after solvent evaporation

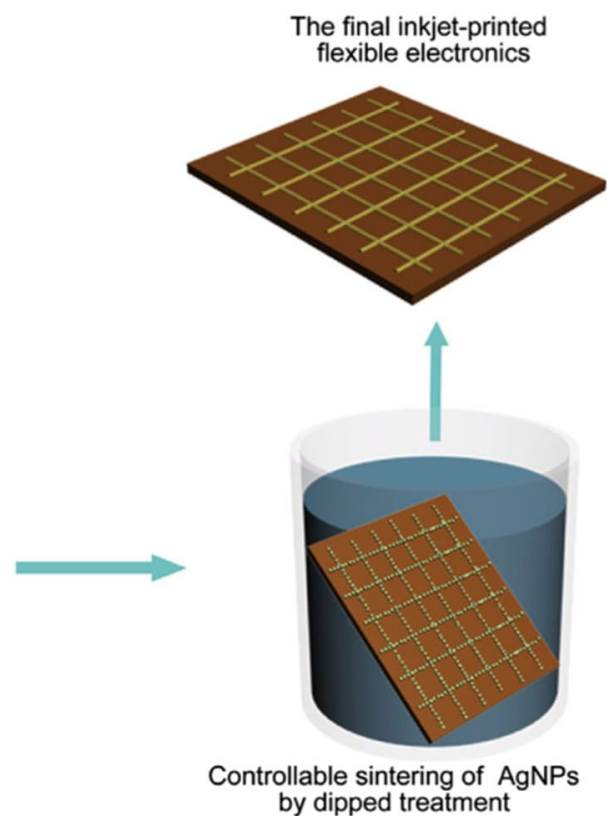

(b)
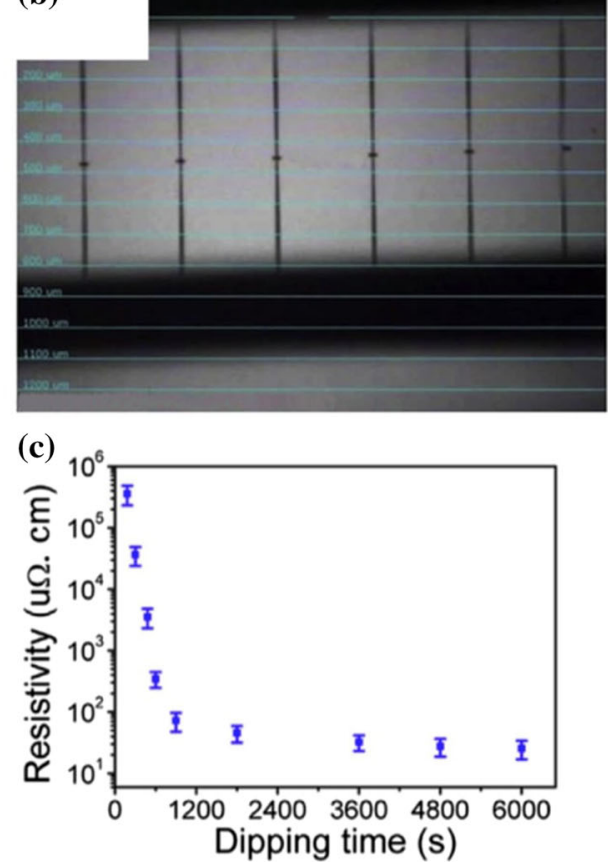

Fig. 7. (a) Schematic illustration of sintering AgNPs by dipped treatment at room temperature, (b) optical image of the excellent printing and (c) the resistivity changes as a function of dipping time (reproduced with permission from Elsevier, 2015). ${ }^{47}$

antenna fabricated by inkjet printing. In 2014, Zhou et al. $^{46}$ reported their work on dodecylamine-protected AgNPs modified by a small amount of dodecanethiol as the co-protective agent. Stable polymer-free conductive ink with AgNP patterns was fabricated using inkjet printing and showed a resistivity of $7.2 \mu \Omega \mathrm{cm}$ after curing at $130^{\circ} \mathrm{C}$ for $10 \mathrm{~min}$.

The following year, in 2015, Zhang and $\mathrm{Zhu}^{47}$ successfully fabricated AgNPs sintered at room temperature by a dipped treatment for inkjetprinted flexible electronics. This technique offered superior controllability, excellent stability and low resistivity in the range of $31.6-26.5 \mu \Omega \mathrm{cm}$. A versatile approach to construct flexible electrocircuits and potential in the field of optoelectronic devices are provided and shown in Fig. 7. These findings presented a new way to sinter the printed pattern at room temperature by dip treatment and still achieve high electrical conductivity. Kastner 
et al. ${ }^{14}$ investigated and optimised the printing of a reactive silver ink made of silver acetate dissolved in aqueous ammonium hydroxide. Based on the findings, the conductivity value of the printed film on glass was $4.42 \times 10^{6} \mathrm{~S} / \mathrm{m}$ after annealing at $120^{\circ} \mathrm{C}$ for several minutes, with the pattern thickness ranging from $150 \mathrm{~nm}$ to $133 \mathrm{~nm}$. For printed silver films on acrylate-based coatings, the conductivity value was $2.9 \times 10^{5} \mathrm{~S} / \mathrm{m}$ with a pattern thickness of $150 \mathrm{~nm}$. Undeniably, AuNPs and AgNPs have excellent electrical conductivity and excellent printability, although various work still needs to be done considering the high cost and high sintering temperature and long sintering required, which make them inadvisable for use on a large scale, especially in industrial applications. ${ }^{48-50}$

Copper nanoparticles (CuNPs) are a good alternative material to gold and silver nanoparticles due to their high electrical conductivity and low price. ${ }^{51}$ Kang et al. ${ }^{15}$ reported a CuNP ink printed on a flexible glass epoxy substrate and sintered at $200^{\circ} \mathrm{C}$ in a furnace under nitrogen atmosphere. From the study, they achieved a stable grain structure and a low resistivity of $36.7 \mathrm{n} \Omega \mathrm{m}$ in a 10-layer printed electrode. Tsai et al. ${ }^{51}$ provided a method for preparing antioxidant conductive copper ink, and a low sheet resistance of $47.6 \mathrm{~m} \Omega / \mathrm{sq}$ at a calcination temperature of $250^{\circ} \mathrm{C}$ in nitrogen atmosphere for $30 \mathrm{~min}$ was produced. These conductive $\mathrm{Cu}$ films could be placed in an atmospheric environment for more than 6 months without oxidation, showing long-term stability.

Recently, Kwon et al. ${ }^{52}$ demonstrated a novel hydrogen plasma sintering method $\left(150^{\circ} \mathrm{C}\right.$ for 10 $20 \mathrm{~min}$ ) that achieved a full reduction and densification of inkjet-printed patterns using a $\mathrm{Cu}$ complex ion ink. The plasma-treated pattern showed a fully densified microstructure with a resistivity of $3.2 \mu \Omega \mathrm{cm}$ (Fig. 8). Xu et al. ${ }^{53}$ investigated the dual effects of water on the performance of copper complex conductive inks with amines as ligands. Blending 2-ethylhexylamine and 2-amino-2-methyl1-propanol as ligands to copper formate could balance the dual effects of water on copper-complex conductive inks. It was found that the printed films had low resistivity, from $9.70 \mu \Omega \mathrm{cm}$ to $14.42 \mu \Omega \mathrm{cm}$, and could be stored for 2 months, which could meet the general requirements of printed electronics. Despite the good electrical conductivity of CuNPs and their low price compared to AuNPs and AgNPs, the main problem of CuNPs is that they are easily oxidised under heat and humidity conditions, which limits their applications. It is also difficult to produce homogeneous nanoparticles and ensure good dispersion within the ink, as the material is not stable in most common solvents (i.e. water, isopropyl alcohol, acetone, etc.) which causes sedimentation. ${ }^{54} \mathrm{CuNPs}$ also require high sintering temperatures and long sintering times to enhance their electrical conductivity, similar to AuNPs and AgNPs.

Carbon nanotubes (CNTs) have drawn considerable attention over other nanomaterials by being electrically heterogeneous (either metallic or semiconducting) in nature. CNTs can be considered as rolled-up graphene sheets with the edges of the sheets joined together to form seamless cylinders. Depending on the number of concentrically rolledup graphene sheets, CNTs are often classified to single-walled (SWCNTs), double-walled (DWCNTs), triple-walled (TWCNTs) and multi-walled (MWCNTs). Their electronic properties depend on the number of CNT walls. ${ }^{55,56}$ The intrinsic electrical resistivity of CNTs (in general) has been found to
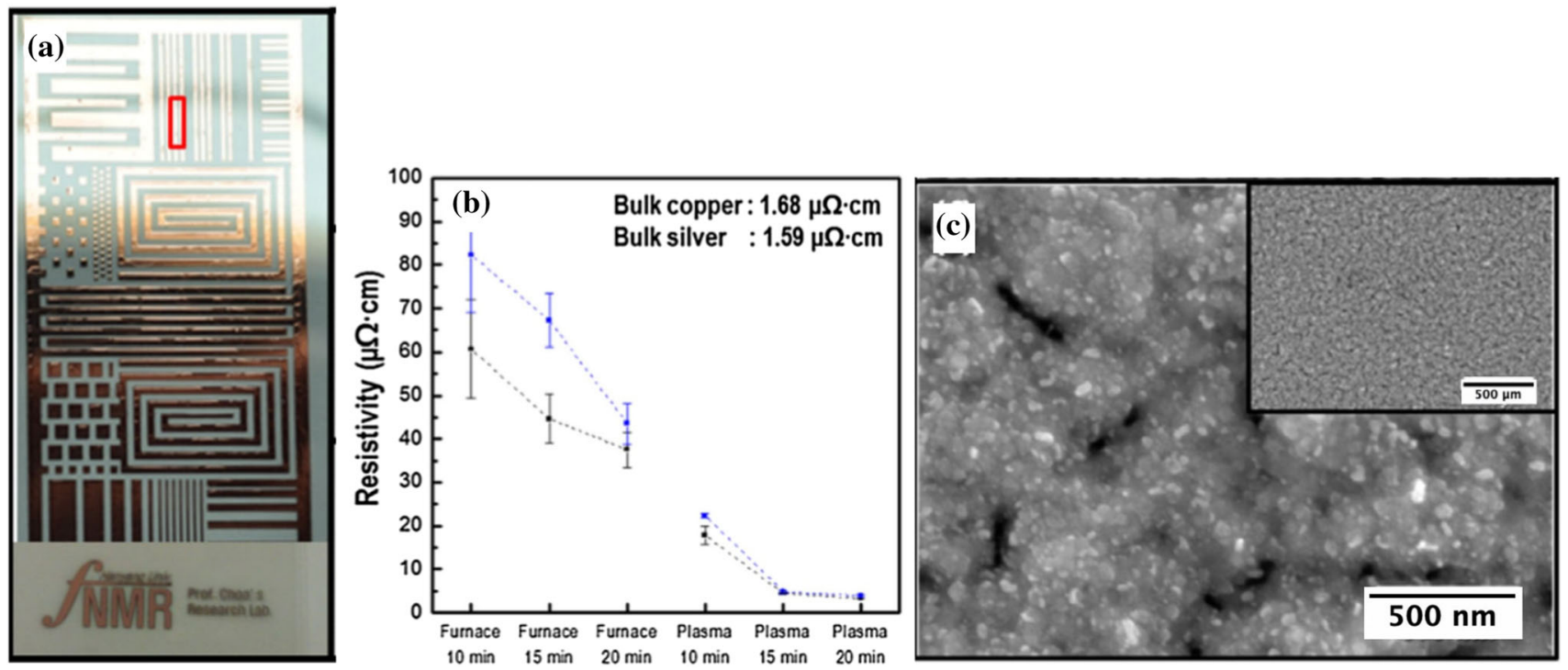

Fig. 8. (a) Plasma-sintered Cu pattern, (b) resistivity of plasma-sintered Cu patterns (black line: as-sintered process, blue line: after 1 month) and (c) SEM image of the Cu conductive tracks sintered for $20 \mathrm{~min}$ (reproduced with permission from Elsevier, 2017). ${ }^{52}$ 


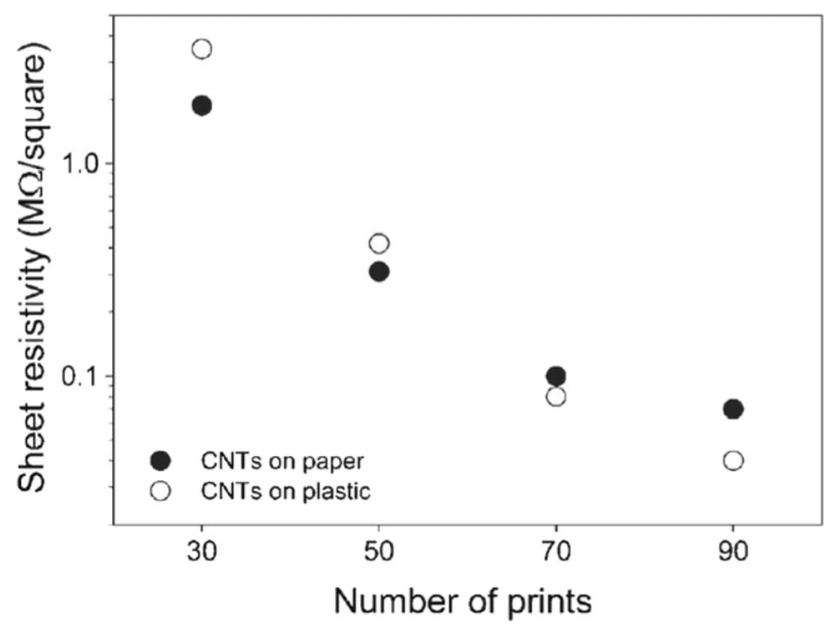

Fig. 9. Sheet resistivity of the CNT patterns printed on paper and transparency foil as a function of print repetition (reproduced with permission from John Wiley and Sons, 2006). ${ }^{57}$

be as low as approximately $10^{-6} \Omega \mathrm{m}$, and this makes them attractive for numerous applications in electronics. ${ }^{27}$

A simple method for generating electrically conductive CNT patterns on paper and plastic surfaces has been demonstrated by Kordás et al. ${ }^{57}$ MWCNTs grown by catalytic chemical vapour deposition (CCVD) were carboxylated and dispersed in water to prepare CNT dispersions suitable for inkjet printing. The sheet resistivity of printed MWCNTs was approximately $40 \mathrm{k} \Omega / \mathrm{sq}$ after multiple printing. This method is applicable to rapid prototyping of resistive components, electromagnetic interference shielding and gas sensors (Fig. 9). Zhou et al. ${ }^{58}$ reported carboxyl-functional MWCNT films produced using inkjet printing. The sheet resistance for the inkjet-printed MWCNT film was $1.1 \times 10^{6} \Omega /$ sq. Inkjet-printed MWCNT films are useful for transparent transistors. However, the stability of CNT suspensions in water is still a topic of interest because the nanoparticles tend to aggregate easily due to their high van der Waals forces of attraction, and there are toxicological issues. ${ }^{59,60}$ Besides that, CNTs require selective growth, functionalisation and sorting processes for separation in order to exploit in full their electronic properties.

\section{Ink Based on Conductive Polymers}

Several conductive polymers have been intensively investigated, considering their low cost and that no sintering process is required; in particular, polyaniline (PANI), polypyrrole (PPy), poly $(3,4-$ ethylenedioxythiophene) poly(styrenesulfonate) (PEDOT:PSS), etc.

PANI has been considered as one of the most promising conducting polymers due to its unique properties, including high electrical conductivity for a polymer material, excellent environmental stability and partial solubility in various solvents. It is the most versatile polymer due to its simplicity, low cost of preparation, thermal and chemical stability and versatile processability. ${ }^{61-63}$

PPy is also a conducting polymer of moderate environmental stability and suitable for multifunctional applications. The electrical and physical properties of the polymeric films are fully dependant on the preparation conditions, such as the electrochemical method of polymerisation, concentration of monomer and doping agent and other synthesis conditions. The polymer is not conducting in its neutral state, and only becomes conducting when it is oxidised. The conductivity value is in the range of $10^{-3}-10^{2} \Omega / \mathrm{cm}$. $^{64-67}$

PEDOT:PSS is a polymer mixture of poly $(3,4-$ ethylenedioxythiophene) (PEDOT) and polystyrene sulfonate (PSS). PEDOT:PSS is also regarded as one of the most technologically promising electrically conductive polymers, due to its water dispersibility, good electrical conductivity and excellent processability. ${ }^{68-70}$ The electrical conductivity of pristine PEDOT:PSS dispersion is less than $10 \mathrm{~S} / \mathrm{cm}$, and can be improved by post-treatment with compounds such as ethylene glycol. ${ }^{71-73}$

Cho et al. ${ }^{74}$ reported an approach to pattern a conducting polymer on various flexible substrates using vapour deposition polymerisation-mediated inkjet printing (VDP-IJP). The sheet resistance of patterned PANI films was $3.8 \times 10^{3} \Omega / \mathrm{sq}$ for an average patterned film thickness of approximately $450 \mathrm{~nm}$ (Fig. 10). Perinka et al. ${ }^{16}$ fabricated inkjetprinted conductive patterns using PEDOT:PSS. Based on the electrical measurements on the printed lines of PEDOT:PSS with an average thickness of $600 \mathrm{~nm}$, the value of the electrical conductivity was $1.1 \mathrm{mS} / \mathrm{cm}$. In 2018 , Chang et al. ${ }^{75}$ fabricated PEDOT:PSS ink with an addition of polyethylene oxide (PEO). The resistance decreased from $2.79 \mathrm{k} \Omega / \mathrm{cm}$ to $0.77 \mathrm{k} \Omega / \mathrm{cm}$ from 20 to 100 printed layers. From our observations, the electrical conductivities of conductive polymers are still considered to be very low compared to those of metallic nanoparticles for some flexible electronic applications. Plus, during preparation of conducting polymer inks, proper viscosity and surface tension should be controlled in order to prevent printing problems such as nozzle clogging and mechanical damage from acidic materials. ${ }^{4}$ Table II presents a brief comparison between existing inks made of several types of conductive polymers with conductive nanomaterials. ${ }^{12-16,47,54,57}$

\section{Graphene-Conductive Material Hybrid Ink}

Recently, research on graphene hybrid inks by adding metallic nanoparticles or conductive polymers to improve the original properties of graphene have been widely studied for specific electronic applications. Based on a comparison of literature reviews of graphene hybrid-based inks reported since 2014, the electrical conductivity of some graphene hybrid-based inks is still considered very 
(a)

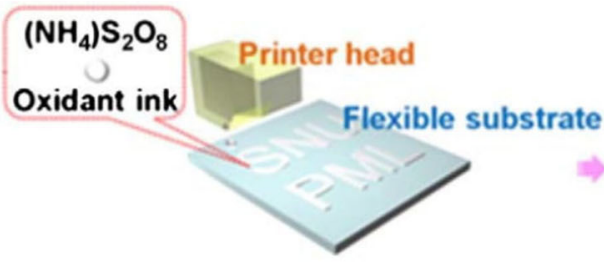

Oxidant printing process

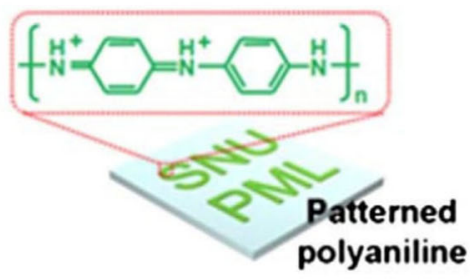

Final product

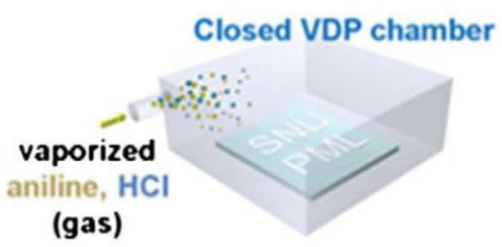

VDP process

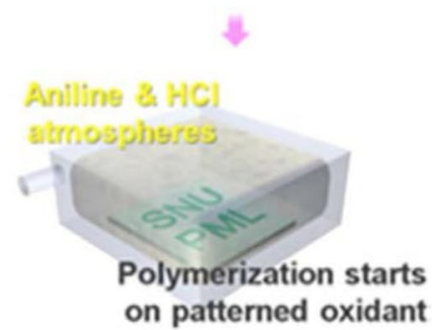

VDP process (b)

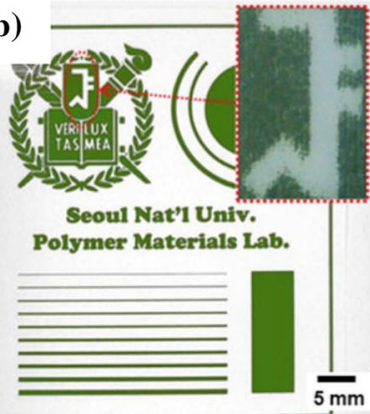

(c)

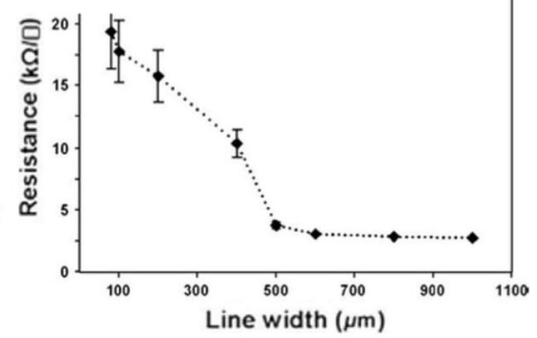

Fig. 10. (a) Schematic diagram of patterning PANI using VDP-IJP, (b) image of PANI patterns prepared by VDP-IJP on photographic paper and magnified optical image of arrowed position (inset) and (c) the sheet resistance of patterned PANI on PET substrate in the dependence on line widths (reproduced with permission from Elsevier, 2010). ${ }^{74}$

low for some flexible electronic applications. The electrical conductivities are reported in the range $0.29-2.0 \times 10^{3} \mathrm{~S} / \mathrm{cm}$. The annealing temperatures used by the researchers are in the range 100 $245^{\circ} \mathrm{C}$. Some efforts still need to be made to improve the electrical properties and annealing temperature before they can be used for practical applications, and thus, as alternatives to graphenebased ink and other conductive material-based ink. Several hybrid inks that have been used by previous researchers include GNP/PANI, Ag/rGO, $\mathrm{Ag} @ \mathrm{Au}$ NTPs-GO, rGO/carbon black and PEDOT:rGO/AuNPs. ${ }^{76-83}$

$\mathrm{Xu}$ et $\mathrm{al} .{ }^{76}$ formulated graphene nanoplatelets/ polyaniline (GNP/PANI) inks for the fabrication of GNP/PANI thin-film electrodes. A GNP/PANI thin film is then printed onto a quartz substrate to give conductivities of GNP and GNP/PANI thin films of $3.67 \mathrm{~S} / \mathrm{cm}(5$ prints, thickness $\sim 41 \mu \mathrm{m})$ and $0.29 \mathrm{~S} /$ $\mathrm{cm}$ (5 prints, thickness $\sim 28 \mu \mathrm{m}$ ), respectively, while that of pure PANI is only $10^{-9} \mathrm{~S} / \mathrm{cm} .{ }^{77}$ Yang et al. $^{78}$ reported a $\mathrm{Ag} / \mathrm{rGO}$ hybrid ink formulated by silver acetate and ethanolamine together with rGO. The resistivity was found to decrease from $0.728 \Omega \mathrm{cm}$ to $1.47 \times 10^{-5} \Omega \mathrm{cm}$ when the annealing temperature was increased from $150^{\circ} \mathrm{C}$ to $245^{\circ} \mathrm{C}$. Deng et al. ${ }^{79}$ prepared AgNP-decorated graphene conductive ink for flexible electronics and obtained a low resistivity of $20 \Omega / \mathrm{sq}$ after annealing at $400^{\circ} \mathrm{C}$ for $30 \mathrm{~min}$. In contrast, Zhang et al. ${ }^{80}$ reported that well-dispersed $\mathrm{Ag} / \mathrm{rGO}$ composite was obtained by anchoring AgNPs on the surface of an rGO sheet, and served as a promising conductive ink filler for printable flexible electronics. An optimum conductivity of $2.0 \times 10^{3} \mathrm{~S} / \mathrm{m}$ with a low annealing temperature around $100^{\circ} \mathrm{C}$ was observed. This simple and cost-effective method is applicable for future application in printed flexible electronics (Fig. 11).

In 2017, Li et al. ${ }^{81}$ synthesised Ag@Au nanotriangle platelets and graphene oxide (Ag@Au NTPsGO) hybrid nanomaterial ink. The patterns showed no undesirable coffee ring effects, and inkjet-printed rGO-based lines of $\sim 7 \mu \mathrm{m}$ width and a film with high transparency of $\sim 98 \%$ were achieved. The value of sheet resistance was $146.8 \Omega / \mathrm{sq}$ after fabrication and $149.5 \Omega / \mathrm{sq}$ after 100 days. This method is applicable to highly stable integrated circuit boards and highly transparent devices (Fig. 12). Ji et al. ${ }^{82}$ fabricated rGO and carbon black hybrid ink with a mixture of ethyl alcohol, ethylene glycol, glycerol and deionised water as solvents and sodium carboxymethyl cellulose as a binding agent. The hybrid inks were inkjet-printed onto photographic paper and dried at $100^{\circ} \mathrm{C}$ for $30 \mathrm{~min}$. The findings showed that the resistance values decreased from $1.43 \mathrm{M} \Omega$ to $0.09 \mathrm{M} \Omega$ from one to five printed layers. The following year, Zhang et al. ${ }^{83}$ prepared PEDOT:rGO/AuNPs (PrGANPs) through in situ reduction for the fabrication of a flexible sensor device using inkjet printing. The PrGANP multilayer films were printed on a PET substrate, varying from 10 to 60 layers. The sheet resistance was found to be decreased with the increase in printed layers, to approximately $500 \mathrm{k} \Omega / \mathrm{sq}$ at 50 printed layers. 
Table II. Comparison of several types of conductive ink materials printed on various substrates

\begin{tabular}{|c|c|c|c|c|}
\hline Ink material & $\begin{array}{c}\text { Resistivity }(\Omega \mathrm{cm}) / \text { Surface } \\
\text { resistance }(\Omega / \mathrm{sq}) / \text { Conduc- } \\
\text { tivity }(\mathrm{S} / \mathrm{cm})\end{array}$ & Advantages & Issues & Refs. \\
\hline AuNPs & $0.8 \times 10^{5} \mathrm{~S} / \mathrm{cm}$ & $\begin{array}{c}\text { High } \\
\text { electrical } \\
\text { conductivity }\end{array}$ & $\begin{array}{c}\text { Expensive and require high sintering } \\
\text { temperature }\end{array}$ & 12 \\
\hline AgNPs & $\begin{array}{l}17 \mu \Omega \mathrm{cm}\left(\text { cured at } 150^{\circ} \mathrm{C} \text { for }\right. \\
50 \mathrm{~min}), \\
3.1 \mu \Omega \mathrm{cm}\left(\text { cured at } 230^{\circ} \mathrm{C} \text { for }\right. \\
50 \mathrm{~min})\end{array}$ & $\begin{array}{l}\text { High } \\
\text { electrical } \\
\text { conductivity }\end{array}$ & $\begin{array}{c}\text { Expensive, silver particles can block the fine } \\
\text { nozzles of an inkjet print head, require high } \\
\text { sintering temperature and long sintering } \\
\text { time }\end{array}$ & 13 \\
\hline AgNPs & $\begin{array}{c}4.42 \times 10^{6} \mathrm{~S} / \mathrm{m}(\text { annealed at } \\
\left.120^{\circ} \mathrm{C}\right)\end{array}$ & & & 14 \\
\hline $\mathrm{AgNPs}_{\mathrm{s}}$ & $\begin{array}{l}31.6-26.5 \mu \Omega \mathrm{cm} \text { (sintered at } \\
\left.\text { room temperature } 30^{\circ} \mathrm{C}\right)\end{array}$ & & & 47 \\
\hline CuNPs & $\begin{array}{c}36.7 \mathrm{n} \Omega \mathrm{m} \text { (sintered at } 200^{\circ} \mathrm{C} \\
\text { in a furnace under nitrogen } \\
\text { atmosphere) }\end{array}$ & $\begin{array}{l}\text { High } \\
\text { electrical } \\
\text { conductivity }\end{array}$ & $\begin{array}{c}\text { Easy oxidation under heat and humidity, } \\
\text { insulating layer, require high sintering } \\
\text { temperature and long sintering time }\end{array}$ & 15 \\
\hline CuNPs & $\begin{array}{c}3.6 \mu \Omega \mathrm{cm} \text { (sintered at } 200^{\circ} \mathrm{C} \\
\text { for } 1 \mathrm{~h} \text { in a furnace under } \\
\text { nitrogen atmosphere) }\end{array}$ & & & 54 \\
\hline PEDOT:PSS & $1.1 \mathrm{mS} / \mathrm{cm}$ & $\begin{array}{l}\text { Does not } \\
\text { require } \\
\text { sintering } \\
\text { process }\end{array}$ & Low electrical conductivity & 16 \\
\hline $\begin{array}{l}\text { Carboxyl func- } \\
\text { tional MWCNT } \\
\text { and PED- } \\
\text { OT:PSS }\end{array}$ & $\begin{array}{l}1.1 \times 10^{6} \Omega / \mathrm{sq}(\mathrm{MWCNT}- \\
\mathrm{COOH}) \text { and } 3.5 \times 10^{3} \Omega / \mathrm{sq} \\
(\mathrm{MWCNT}-\mathrm{COOH}-\mathrm{PSS})\end{array}$ & $\begin{array}{l}\text { High } \\
\text { electrical } \\
\text { conductivity }\end{array}$ & Toxicological effect & 57 \\
\hline
\end{tabular}

\section{CONDUCTIVE INK COMPOSITIONS}

Based on intended applications and desired printing process, there are some factors to be considered for conductive ink formulations. These factors are printing methods, conductive materials, factors affecting ink performance and factors affecting conductivity. ${ }^{84,85}$ Apart from these factors, Yang and Wang ${ }^{19}$ reported that conductive materialbased inks should be stable against aggregation and precipitation in order to provide reproducible performance. Conductive material-based inks trend to agglomerate; this agglomeration leads to increasing ink viscosity, which leads to changes in ink properties and clogging of printhead nozzles during printing. This agglomeration of conductive materials can be prevented by introducing additives into the inks, such as dispersants, surfactants, adhesion promoters, stabilising agents and others.

As is known, conductive material-based inks are suspensions of conductive materials in media including additives; normally, these additives and media are not inherently conductive. Volumes of conductive materials are generally maintained above the substrate surface, and thus there is a minimum volume required in order to achieve interparticle connectivity. Besides, these non-conductive materials remaining in the printed conductive patterns reduce the conductivity. Hence, removing nonconductive materials leads to better connections between conductive materials, forming conductive patterns with increased conductivity.

A conductive ink is a multicomponent system, containing conductive materials in liquid form. Fundamentally, inks are defined by mixtures of water, pigment or dye, humectant and other additives such as rheology and surface tension modifiers, binders and defoamers. These additives enable optimal performance of the conductive ink. ${ }^{28,86,87}$ Conductive inks can be further divided into aqueous-based, solvent-based, oil-based, hot-melt and UV-curable inks.

\section{Aqueous-Based Ink}

Aqueous-based inks were the first to be used in inkjet printing and are still common today. Aqueous-based inks use water as primary solvent. Inks can contain pigment, dye or a combination of both pigment and dye as colourant, and the pigment can be either of organic (i.e. alcohols or glycols) or inorganic material. Typically, aqueous-based inks are used in corrugated packaging or décor printing on absorbent papers, and flexible plastic packaging. They have also recently been investigated for the ceramic tile market. For example, aqueous-based inks in high-speed inkjet printing are held on absorbent substrates such as laminations on plain paper to form décor papers. ${ }^{88}$ 
(a)

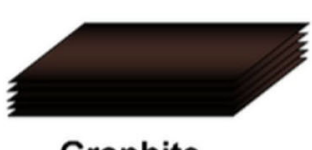

Graphite

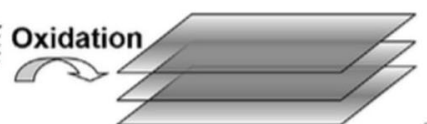

Graphite Oxide (b)

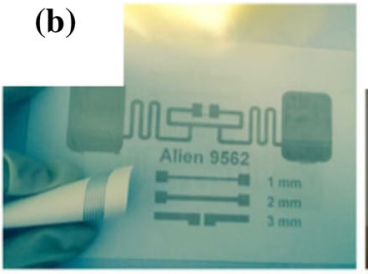

(d) (c)

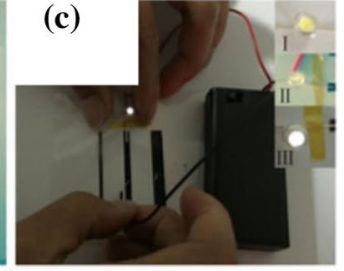

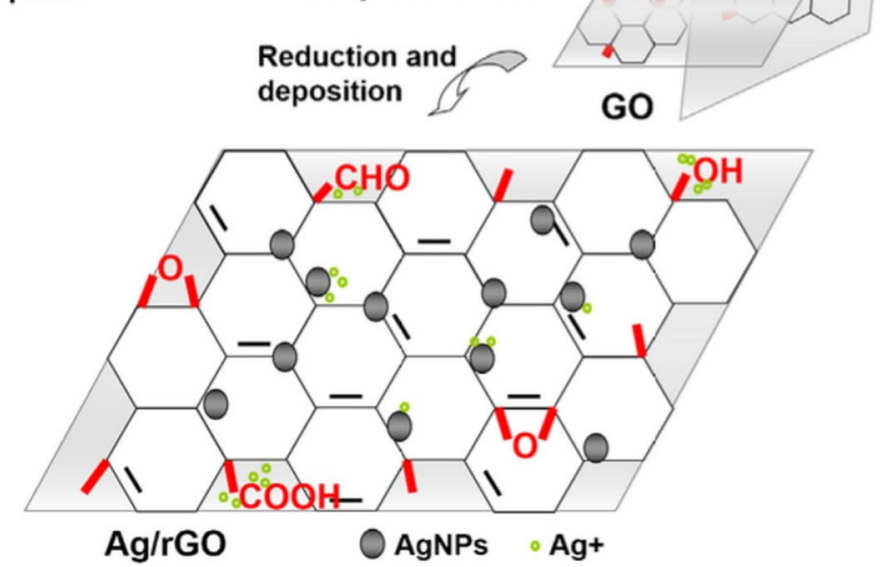

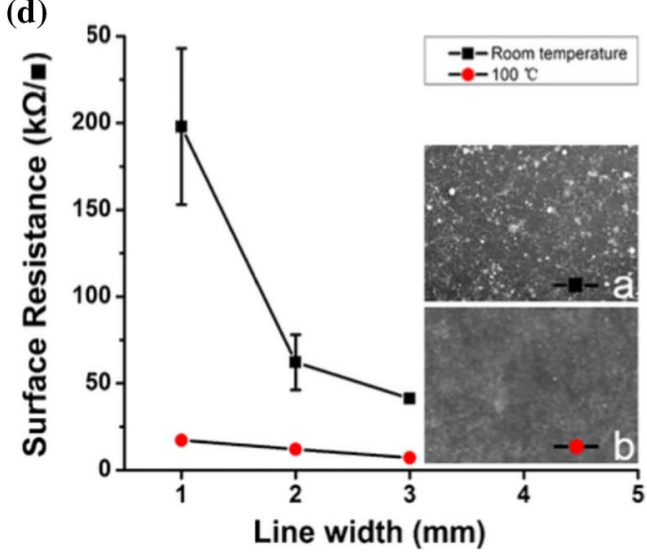

Fig. 11. (a) The route to synthesize Ag/rGO composite by reducing both the Ag and GO, (b) different patterns obtained by inkjet printing on office paper, (c) conductive tracks in different width on PET for circuit test and (d) surface resistance and the surface morphology of the printed conductive tracks (reproduced with permission from Elsevier, 2016). ${ }^{80}$

(a)

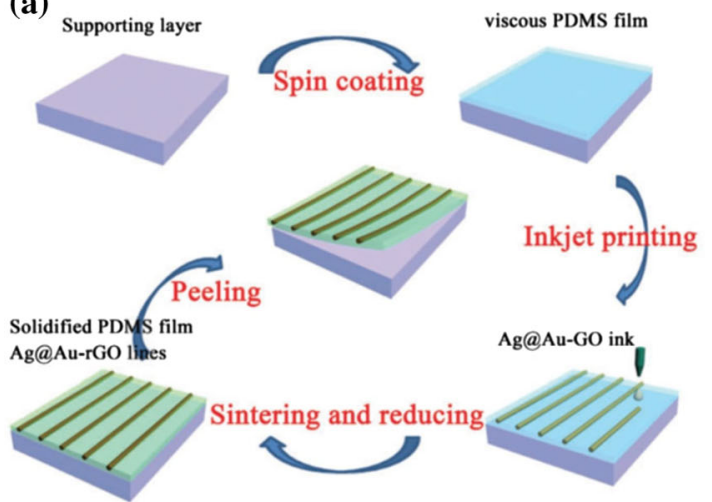

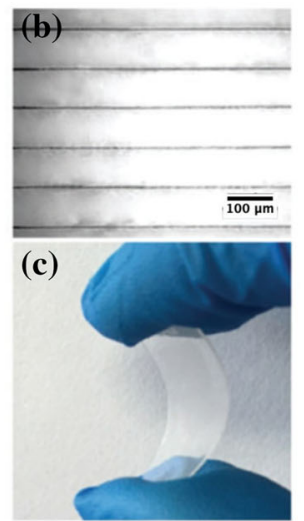

Fig. 12. (a) Schematic illustration of the inkjet-printed processes, (b) optical microscope image of the printed lines of Ag@Au NTPs-rGO, (c) photograph of flexible transparent circuits bent by fingers and (d) sheet resistance against transmittance of inkjet-printed rGO-based electrodes, compared with other transparent linearpolyester (LPE)-synthesised graphene-based electrodes from previous studies (reproduced with permission from the Royal Society of Chemistry, 2017). ${ }^{81}$

There are some difficulties with the volatility of ink in an open system such as inkjet printing and drying on substrates, especially non-absorbent substrates. Therefore, addition of non-volatile solvents, humectants, surfactants and special additives improves the reliability and performance of inks during and after printing. Besides, additional functional materials such as emulsion polymers can be chosen as colourants in specific applications. The surface tension properties of aqueous-based inks depend on the speed of migration of surface-active compositions such as surfactants, solvent and polymers. Additionally, surfactants perform an important role in the wetting characteristics of ink inside the printhead and on the substrate surface. Moreover, approaches in ink and printing hardware technology have been focused on functional inks, where they can be applied to less absorbing substrates such as coated paper and non-absorbing substrates such as textile fibres or films.

A previous work by Tai and Yang ${ }^{89}$ reported the high-efficiency fabrication of an aqueous conductive ink with $\mathrm{Ag}$ nanoflakes for paper-based flexible electronics by direct writing. Dang et al. ${ }^{90}$ reported that an aqueous conductive $\mathrm{Cu}$ nanosheet ink was prepared for flexible electronics. $\mathrm{Cu}$ nanosheets 
were mixed with carboxymethyl cellulose containing water and methanol. The $\mathrm{Cu}$ nanosheet circuits displayed excellent conductive performance (Fig. 13). Majee et al. ${ }^{35}$ reported that a GNP ink was prepared by exfoliating GNPs in water mixed with a cellulose stabiliser ((hydroxypropyl)methyl cellulose). The availability of water-based GNP inks for efficient and reliable conductivity enhancement has offered a pathway for the application of GNPs in printed electronic devices.

\section{Solvent-Based Ink}

Solvent-based inks make up the highest volume of conductive ink used in industry. They are largely made up of solvent, pigmented colourant, resin and a glossing agent. ${ }^{91}$ Solvent-based inks are of two types: (1) inks that contain a more aggressive solvent (i.e. 2-butoxyethyl acetate and cyclohexanone), which have a wider range of substrate compatibility, and (2) eco-solvent inks, which contain a less aggressive solvent (i.e. dipropylene glycol monomethyl ether), but are still considered hazardous chemicals. Solvent-based inks offer high durability and fast drying, but emit volatile organic compounds. Thus, special manufacturing controls are needed. The trend in solventbased inks in recent years is moving towards reducing volatility and improving health and safety profiles; for example, ecological and toxicological profiles.

A solvent-based conductive ink for inkjet printing produced by incorporation of expanded graphite with non-toxic solvents has been reported in a work by Arapov et al. ${ }^{30}$ Kell et al ${ }^{92}$ prepared an Ag-based conductive ink with an aliphatic solvent and polymer for flexible electronics. The conductive Ag pattern exhibited low resistance and high adhesion to the substrate.

\section{Oil-Based Ink}

Oil-based inks use a very slow-drying carrier fluid derived from mineral oil; hence, the term 'oil-based'. Printing of ceramic tiles and coding on corrugated boxes are the main applications of oil-based inks. Historically, oil-based ink aimed to use purified petroleum distillates. This is due to the oil's naturally low surface tension; therefore, a mixture of oils can control the viscosity, rate of absorption and wettability on the surface without the need for surfactants. However, oil-based inks are very slowdrying after printing. Recently, oil-based inks have shifted to sustainable alternatives such as vegetable oil derivative-based inks. Oil-based inks are useful dispersing media for nanoparticles, by which their compatibility with nanoparticles and stabilising agents can be advantageous for the dispersion
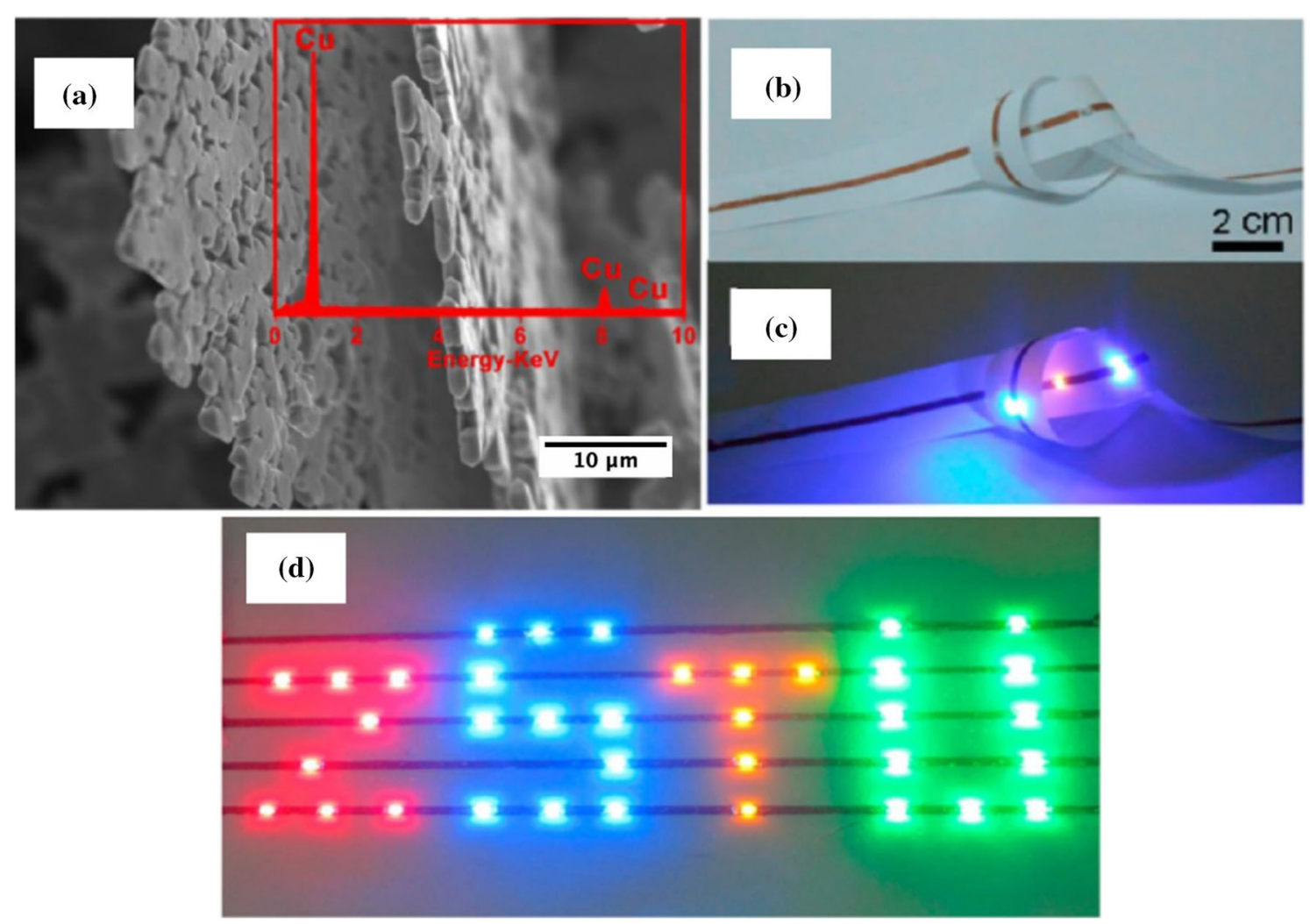

Fig. 13. (a) SEM image of Cu nanosheets (inset is XRD patterns of Cu nanosheets), photographic images of the Cu nanosheet circuit that can support the LED chips on photocopy paper (b) without power and (c) powered by a 9-V battery and (d) optical image of a flexible paper display containing an LED array on paper (reproduced with permission from the American Chemical Society, 2014)..$^{90}$ 
and stabilisation of suspensions. As the droplets can be formed with very small quantities, oil-based inks can be used for high-resolution printing. ${ }^{88}$ As reported in a work by Zhang et al., ${ }^{93}$ a CuNP oilbased ink can be stored for 30 days under ambient conditions and the ink printed via silk-screen printing with low electrical resistivity.

\section{Hot-Melt Ink}

Hot-melt inks are gel-like at room temperature, and are also known as phase-change inks. Hot-melt ink is a special type of ink compared to others, where printing is required at more elevated temperatures with high temperature-compatible printhead systems. These inks offer several advantages: they are fast-drying, environmentally friendly and exhibit good print quality due to rapid solidification. However, they suffer from poor durability and abrasion resistance. Commonly, wax and resin materials with varied melting points combined with pigment or dye formulate the hot-melt inks, and additives acting as plasticisers are added to control the surface tension and final properties. In addition, hot-melt inks can be used in applications such as the printing of barcodes on non-porous substrates. ${ }^{88}$

\section{UV-Curable Ink}

UV inkjet inks are inks that are cured with the use of an ultraviolet light and have been used in wide-format printing of rigid substrates. UV inks offer instant drying that leaves the print completely cured, as no solvents penetrate the substrate once it leaves the printer. However, there are some challenges with UV-curing inks, such as photoinitiator migration in packaging, and some solid curable components remaining after the curing process. In addition, UV inks are quite high in cost and have health-and-safety-related issues. ${ }^{88}$

Hwang et al. ${ }^{94}$ produced a highly conductive $\mathrm{Cu}$ nano-ink film using an ultra-high-speed photonic sintering method involving flash white light (FWL) combined with near-infrared (NIR) and deep UV light irradiation, as shown in Fig. 14. Optimally sintered $\mathrm{Cu}$ nano-ink films produced using a deep UV-assisted FWL sintering technique had the lowest resistivity of $7.62 \mu \Omega \mathrm{cm}$, which was higher than the bulk $\mathrm{Cu}$ film $(1.68 \mu \Omega \mathrm{cm})$.

Table III presents the pros and cons of various types of conductive ink compositions including aqueous-based, solvent-based, oil-based, hot-melt and UV-curable inks from the literature. ${ }^{88,94,95,97-99}$

\section{CONDUCTIVE INK PROPERTIES}

There are many printing techniques to deposit the conductive ink onto substrates; for example, flexography, inkjet, gravure and screen printing. Basically, the characteristics of a good conductive ink are good printability, good adhesion with the substrate, high resolution, minimum printer maintenance and long shelf life. ${ }^{28}$ However, properties of conductive inks such as density, viscosity, surface tension, elasticity, velocity, droplet size and impact of droplets on a dry surface affect the droplet jetting during printing and the final properties of printed conductive patterns. Among these characteristics, physical properties such as viscosity and surface tension dominate both the behaviour of the conductive ink during printing and the quality of printed conductive patterns, especially for inkjet printing. ${ }^{18}$ A printable conductive ink requires a low viscosity and high surface tension in order to flow through the nozzle easily without leakage, drying out, breaking away or coagulation within the nozzle.

\section{Viscosity}

Viscosity is a fundamental characteristic of all fluids, and measures the resistance of a liquid to flow or shear deformation. This resistance is caused by cohesive intermolecular forces, which give rise to friction between adjacent layers of the fluid in relative motion. Numerous parameters affect the viscosity (i.e. temperature and pressure) as this is considered to be one of the critical properties of printing inks. The viscosity value decreases when the temperature increases. ${ }^{18,100}$

Different printing methods require different conductive ink viscosity, as shown in Table IV. Inkjet printing requires a lower viscosity compared to other printing methods because an ink with high viscosity will clog the nozzle. ${ }^{24}$ The results indicate that the rheological behaviour and dispersion state of a conductive ink used in inkjet printing significantly affect the ink's printability and the quality of the pattern produced, and so they should be carefully controlled. ${ }^{101}$

According to Ihalainen et al., ${ }^{102}$ the viscosity of an ideal conductive ink for inkjet printing should be in the range of $1-20 \mathrm{mPas}$ to avoid problems during the printing process, including nozzle clogging, and satellite or double droplets. If the conductive ink is highly viscous, the jetting frequency will be reduced as the rate of reservoir filling is decreased. For a conductive ink that is insufficiently viscous, highfrequency jetting may cause unstable droplet ejection.

Figure 15 illustrates the rheological behaviour of graphene ink at various temperatures. ${ }^{101}$ The viscosity of the conductive ink is considered to be stable at a high shear rate and then to decrease with an increase in shear rate, exhibiting the common behaviour of fluid called shear-thinning or pseudoplasticity. It can also be observed from Fig. 15 that the viscosity values decrease with an increase in temperature. The viscosity of graphene ink at room temperature is between $7.5 \mathrm{mPas}$ and $10 \mathrm{mPas}$, which can be considered as acceptable for inkjet printing. According to Shaw ${ }^{103}$ and Woo et al., ${ }^{104}$ the viscosity is higher at low shear rate due to the attraction between the particles creating 


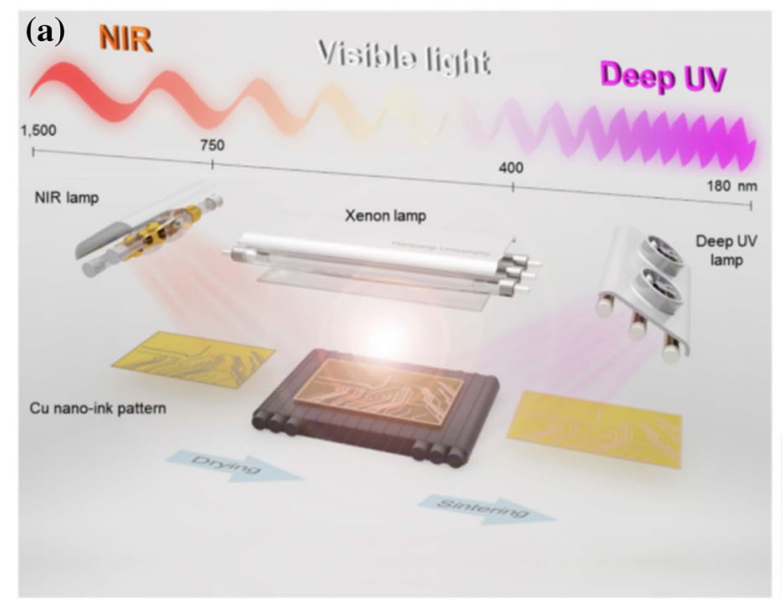

(b)

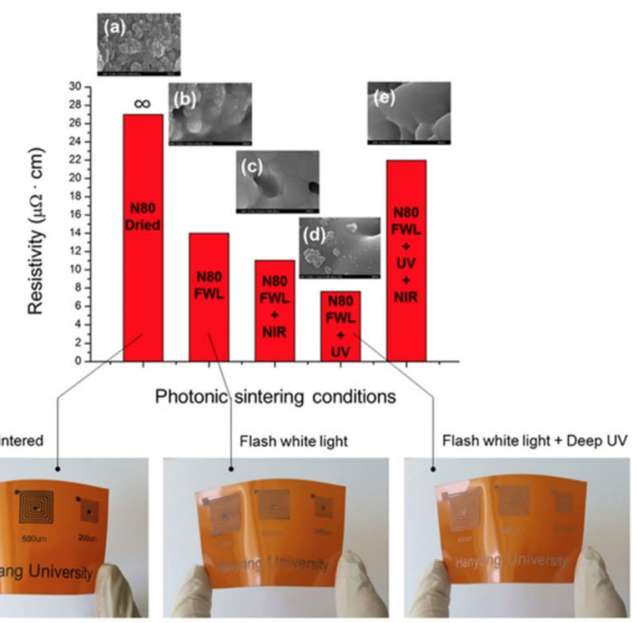

Fig. 14. (a) Schematic view of all-photonic drying and sintering process of Cu nano-ink using NIR, flash white light and deep UV, and (b) comparison of the resistivity of the Cu films sintered by different sintering methods ${ }^{94}$ (reproduced with permission from Nature, 2016).

flocculation in the inks, causing an immobility of the solvent suspending the particles. In contrast, the viscosity at a higher shear rate is lower, as the flocculation breaks down and aids the mobility of solvent entrapped between particles.

\section{Surface Tension}

According to the cohesive intermolecular force in the liquid, there is an asymmetric attractive force between the molecules at the interface between liquid and air, which gives rise to tension at the surface, as displayed in Fig. 16a. Surface tension is highly dependent on temperature, usually decreasing slightly with increasing temperature.

Molecules in the liquid also exhibit adhesion as well as cohesion, where the adhesive force and attractive force between different molecules enable the liquid to adhere onto the surface of materials. In the deposition of ink droplets onto a substrate surface, the shape of the droplet after deposition depends on the relative strengths of these molecular forces. Surface tension of the liquid causes the force to act perpendicularly to the surface, and can be measured in terms of surface energy. In an ideal situation of a droplet spreading onto a substrate surface, only one equilibrium contact angle is obtained, as shown in Fig. 16b. The surface energy relation between liquid, solid and gas interfaces can be expressed by Young's equation: $\gamma_{\mathrm{S}}=\gamma_{\mathrm{SL}}+\gamma_{\mathrm{L}} \cos$ $\theta$, where $\gamma_{\mathrm{L}}$ is the surface energy of the liquid, $\gamma_{\mathrm{SL}}$ is the surface energy at the solid/liquid interface, and $\gamma_{\mathrm{S}}$ is the surface energy of the solid. ${ }^{105}$ If the adhesive force dominates, the ink droplet will be pulled onto the surface; this is known as wet characteristics or hydrophilicity. In contrast, if the adhesive force is negligible, the ink droplet will tend to bead up on the surface, known as hydrophobicity. This means that the ink droplet has a cohesive force into the droplet that is greater than the adhesive force between the droplet and the substrate surface. A comparison of ink droplets on surfaces is illustrated in Fig. 16c and d. In practice, there are two relatively reproducible angles in the largest and smallest contact angles where the difference between these two angles is often called contact angle hysteresis. Figure 17 illustrates the different wetting behaviours of droplets spreading on a substrate surface. ${ }^{18}$

The recommended values of surface tension for inkjet printing should be within the range 25$50 \mathrm{mN} \mathrm{m}^{-1}$ in order to generate a stream of droplets. ${ }^{106} \mathrm{Li}$ et al. ${ }^{107}$ reported that the surface tension of a GO dispersion increased slowly when the concentration of GO increased. The concentration of GO should be as high as possible within a certain range to ensure the printed circles have enough thickness to be of good conductivity. However, the surface tension of GO dispersion was too high to print $\left(>70 \mathrm{mN} \mathrm{m}^{-1}\right)$. Thus, surfactants (i.e. SDS and TX-100) were introduced into the GO dispersion, as these compounds could efficiently lower the surface tension between two liquids or between a liquid and a solid. The surface tension of GO/SDS hybrid dispersion decreased with an increase in dispersion concentration. Note that the amount of surfactant should be as small as possible. Table V presents the comparison of viscosity and surface tension of various types of conductive inks from literature..$^{23,26,27,79,108-111}$

\section{INKJET PRINTING FOR FLEXIBLE ELECTRONICS}

Flexible electronics, often called as flex circuits, have created a vibrant market over the past few years. Several factors have contributed to the increase in flexible electronics, including more ruggedness, bendability, light weight, portability and lower cost of production compared to rigid- 


\section{Table III. Comparison of pros and cons of various types of conductive ink compositions}

\begin{tabular}{|c|c|c|c|c|}
\hline $\begin{array}{l}\text { Types of } \\
\text { conductive } \\
\text { ink }\end{array}$ & $\begin{array}{l}\text { Example of ink } \\
\text { formulations }\end{array}$ & Advantages & Issues & Refs. \\
\hline $\begin{array}{l}\text { Aqueous- } \\
\text { based ink }\end{array}$ & $\begin{array}{c}\text { CuNPs/deionised water/2- } \\
\text { methoxyethanol/ } \\
\text { glycerol/EG } \\
\text { GNPs/water/water- } \\
\text { soluble cellulose } \\
\text { stabiliser } \\
\text { (hydroxypropyl methyl } \\
\text { cellulose)/2,3-butanediol } \\
\text { Ag/GO/distilled water/ } \\
\text { ethanol/EG }\end{array}$ & $\begin{array}{l}\text { High surface tension } \\
\text { Superior dispersion stability due } \\
\text { to water as dispersion medium } \\
\text { and polyelectrolyte as a } \\
\text { dispersant } \\
\text { Low ink concentration } \\
\text { (usually } \sim 1 \mathrm{mg} / \mathrm{mL}) \\
\text { Does not require any post- } \\
\text { treatment process or low- } \\
\text { temperature treatment } \\
\text { Cost-effective and } \\
\text { environmentally friendly }\end{array}$ & $\begin{array}{c}\text { Require porous or treated } \\
\text { substrates or lamination to } \\
\text { impart durability } \\
\text { Ink tends not to adhere to non- } \\
\text { porous substrates } \\
\text { Inks are relatively volatile in } \\
\text { printhead }\end{array}$ & 88,95 \\
\hline $\begin{array}{l}\text { Solvent- } \\
\text { based ink }\end{array}$ & $\begin{array}{c}\text { Pristine graphene sheets/ } \\
\text { EC/cyclohexanone } \\
\text { CuNPs/EG/2- } \\
\text { methoxyethanol/ } \\
\text { methanol } \\
\text { AgNPs/butyl glycol } \\
\text { acetate/organic Ag salts/ } \\
\text { anionic polymeric } \\
\text { surfactant }\end{array}$ & $\begin{array}{l}\text { Able to adhere to a variety of } \\
\text { substrates and fast drying time } \\
\text { Inexpensive cost, exceptional } \\
\text { print quality and image } \\
\text { durability } \\
\text { Ink can stable more than } \\
6 \text { months }\end{array}$ & $\begin{array}{c}\text { Presence of polymeric surfactants } \\
\text { hinders the formation of } \\
\text { conductive layer } \\
\text { Higher annealing temperature } \\
\text { than decomposition } \\
\text { temperature of polymeric } \\
\text { surfactants } \\
\text { Non-environmentally friendly } \\
\text { and requirement for high } \\
\text { maintenance due to potential of } \\
\text { fast-drying fluid blocking the } \\
\text { print head nozzle }\end{array}$ & $95-97$ \\
\hline $\begin{array}{l}\text { Oil-based } \\
\text { ink }\end{array}$ & $\begin{array}{c}\text { CuNPs/ethylene glycol } \\
\text { butyl ether/ } \\
\text { methylcellulose/other } \\
\text { additives (mixed oil } \\
\text { solvents) } \\
\text { Graphene/diluted oil } \\
\text { dispersion/water }\end{array}$ & $\begin{array}{l}\text { Can be completely oil, non- } \\
\text { aqueous fluid, water-in-oil } \\
\text { emulsion, water-in-non- } \\
\text { aqueous emulsion, brine-in-oil } \\
\text { emulsion or brine-in- } \\
\text { nonaqueous emulsion } \\
\text { Good dispersion with low } \\
\text { resistivity }\end{array}$ & $\begin{array}{c}\text { Preferred in certain conditions } \\
\text { such as sensitive scales or high- } \\
\text { pressure high-temperature } \\
\text { condition where corrosion is } \\
\text { abundant }\end{array}$ & 98 \\
\hline Hot melt ink & $\begin{array}{c}\text { Paraffin wax/EVA/ } \\
\text { polyamide resin/low mol } \\
\text { alcohol I/blowing agent } \\
\text { Low-molecular-weight PE } \\
\text { wax/polyamide resin/ } \\
\text { low-mol alcohol/blowing } \\
\text { agent }\end{array}$ & $\begin{array}{c}\text { In solid form and melt before } \\
\text { being printed } \\
\text { Easy to control the printing } \\
\text { quality } \\
\text { Low equipment cost, cleanliness } \\
\text { and high reliability } \\
\text { Contains additives to improve the } \\
\text { inks performance } \\
\text { Safe and environmentally } \\
\text { friendly, very fast-drying and } \\
\text { exhibits good opacity }\end{array}$ & $\begin{array}{c}\text { Lack of durability and poor } \\
\text { abrasion resistance } \\
\text { Temperature of substrate and } \\
\text { inks need to be controlled } \\
\text { Inks must be stable and non- } \\
\text { reactive to materials in the } \\
\text { printhead } \\
\text { Rapid solidification in less than } \\
\text { millisecond }\end{array}$ & 95,99 \\
\hline $\begin{array}{l}\text { UV-curable } \\
\text { ink }\end{array}$ & $\begin{array}{c}\text { CuNPs/diethylene glycol/ } \\
\operatorname{poly}(N- \\
\text { vinylpyrrolidone })\end{array}$ & $\begin{array}{c}\text { Stable until irradiated with a } \\
\text { particular wavelength and } \\
\text { intensity of light } \\
\text { High reliability and } \\
\text { environmentally friendly } \\
\text { Curing lamps consume less } \\
\text { energy than conventional } \\
\text { dryers } \\
\text { Less wastage of ink and } \\
\text { consistent ink quality as no } \\
\text { solvent evaporation occurs }\end{array}$ & $\begin{array}{l}\text { High cost and facility } \\
\text { requirements for UV curing } \\
\text { hardware }\end{array}$ & 94,95 \\
\hline
\end{tabular}


Table IV. Comparison of ink viscosity and line dimension of different printing methods

\begin{tabular}{|c|c|c|c|c|}
\hline Printing methods & Ink viscosity (cP) & Line width $(\mu \mathrm{m})$ & Line thickness $(\mu \mathrm{m})$ & Speed (m/min) \\
\hline Inkjet & $10-20$ & $30-50$ & Approx. 1 & Slow (rotary screen: $10 \mathrm{~m} / \mathrm{s}$ ) \\
\hline Offset & $100-10000$ & 10 & 10 & Middle-fast (approx. 1000) \\
\hline Gravure & $100-1000$ & $10-50$ & Approx. 1 & Fast (approx. 1000) \\
\hline Flexography & $50-500$ & $45-100$ & $<1$ & Fast (approx. 500) \\
\hline Screen & $500-5000$ & $30-50$ & $5-100$ & Middle (approx. 70) \\
\hline
\end{tabular}

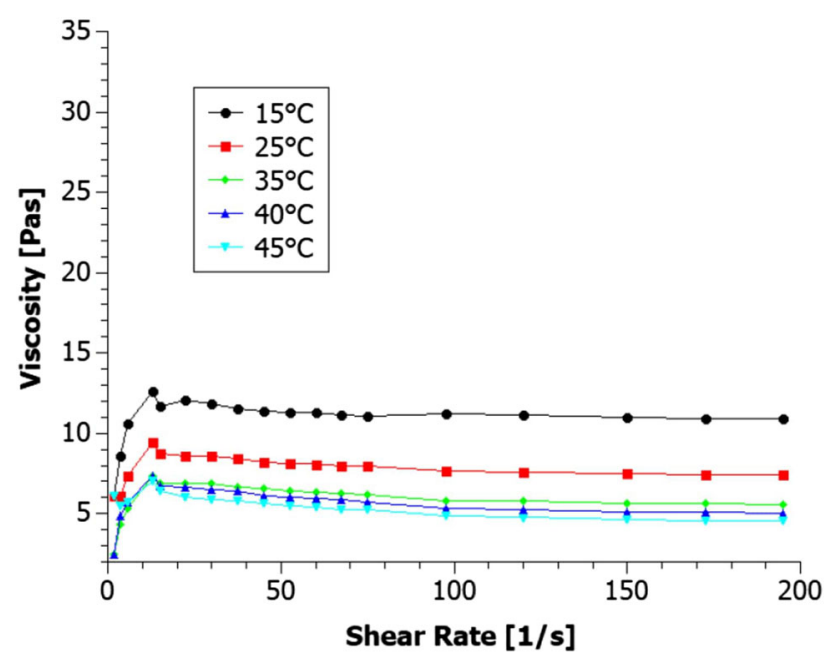

Fig. 15. Viscosity curves of graphene ink with dispersing agent at various temperatures (reproduced with permission from MDPI, 2018). ${ }^{101}$

substrate electronics. In order to make the structure flexible, all the components must bend to some degree without losing their function. Two basic approaches have been widely used to make flexible electronics: (1) transfer and bonding of completed circuits to a flexible substrate and (2) fabrication of the circuits directly onto the flexible substrate. ${ }^{112}$

Two main approaches are involved in the fabrication of flexible electronics: (1) contact printing and (2) non-contact printing. In contact printing, the patterned structures with inked surfaces acquire physical contact with the substrate. Several examples of contact printing technologies are flexography, gravure, soft lithography and roll-to-roll (R2R) printing. For non-contact printing, the solution is dispensed through openings or nozzles, and structures are defined by moving the stage (substrate holder) in a pre-programmed pattern. It involves screen-printing, aerosol jet, 3D printing, spray coating and inkjet printing. ${ }^{17}$ Table VI presents the pros and cons of various printing techniques for the fabrication of flexible electronics. Of these printing techniques, inkjet printing technologies have received more attention by virtue of their numerous advantages, including simplicity, affordability, speed, adaptability to the fabrication process, reduced material wastage, high pattern resolution and easy control by adjustment of a few parameters. ${ }^{17,85,113-125}$

Inkjet printing, known as digital printing, is a non-contact printing technique where micro-sized ink droplets are ejected directly onto a substrate from a jet device driven by an electronic signal. Inkjet printing is considered as a popular method in the conventional printing industry due to fine pattern generation, non-contact injection, solutionsaving effects, high repeatability and scalability. Inkjet printing technologies can be classified as continuous or drop-on-demand, as illustrated in Fig. 18. ${ }^{126-128}$

In continuous inkjet printing, the ink is pumped through a nozzle, which is charged according to the image and controlled electronically to aim the droplets onto the substrate. The excess droplets are recirculated from the gutter. This method has a fast rate of $0.5 \mu \mathrm{L}$ droplet generation at $80-$ $100 \mathrm{kHz}{ }^{129,130}$ Today, most inkjet printers are based on the drop-formation process, known as demand-mode printing. This method has a slower ejection rate of $2-500 \mathrm{pL}$ droplet generation at $30 \mathrm{kHz}$. The demand-mode method provides smaller drops and higher placement accuracy than continuous inkjet printing, and does not need a recirculation system. Therefore, this method is of simple design and results in less wasted ink. ${ }^{129-131}$ Table VII shows a comparison of drop-on-demand inkjet printing details from the literature. This technique has been used to fabricate electronics by jetting conductive inks onto certain substrates to manufacture various devices, due to its versatility, which makes it applicable to various substrates. $^{26,30,31,33-35,38,39,80,132}$

Majee et al. ${ }^{35}$ formulated a water-based graphene ink by a shear-exfoliation process. The graphene ink at a concentration of approximately $8.5 \mathrm{mg} / \mathrm{mL}$ has a viscosity of $9-12 \mathrm{mPas}$ at $30^{\circ} \mathrm{C}$, and was printed using a Dimatix DMP-2831 printer equipped with a $10 \mathrm{pL}$ drop cartridge. Drop spacing was maintained at $20 \mu \mathrm{m}$ for all printed patterns. These conditions are suitable for the inkjet printing process. More recently, Karim et al. ${ }^{133}$ formulated an rGO ink by rigorous stirring, with a viscosity of $1.35 \mathrm{mPas}$ and surface tension of $65 \mathrm{mN} \mathrm{m}^{-1}$. The film was printed using Dimatix DMP-2800 printer equipped with a $10 \mathrm{pL}$ drop cartridge. The nozzle plate consisted of a 


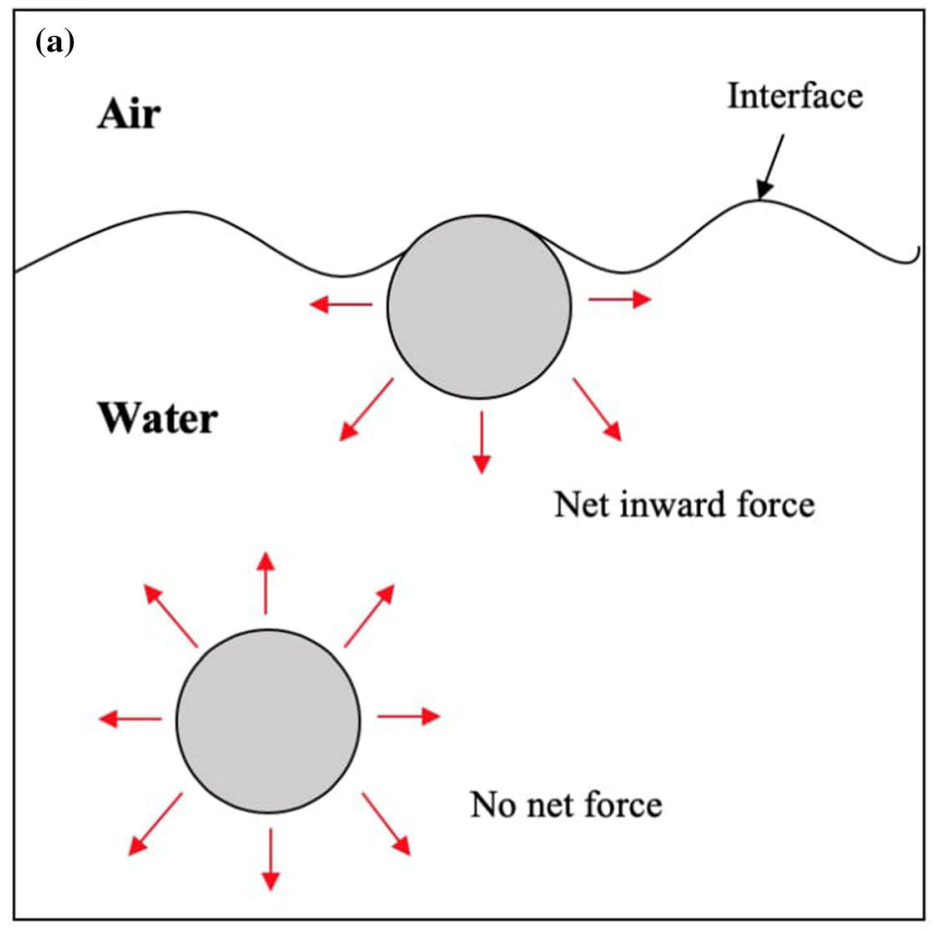

(b)

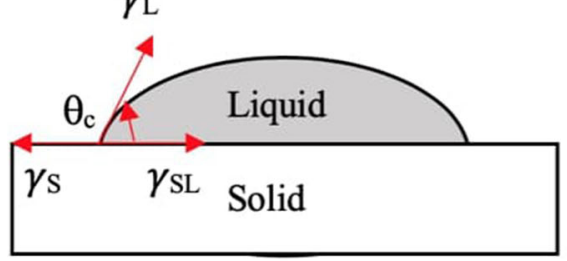

(c)

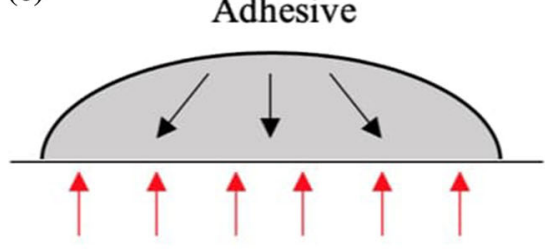

Destination Surface (d) Adhesive

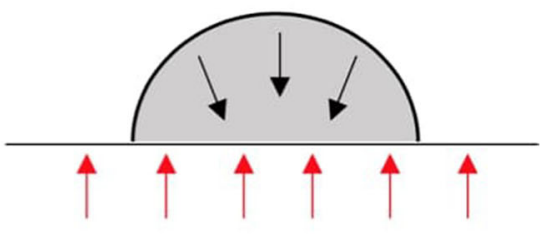

Destination Surface

Fig. 16. Schematic of (a) surface tension from intermolecular forces, (b) droplet onto substrate surface with an ideal contact angle $\left(\theta_{\mathrm{c}}\right)$, and comparison of droplet shapes with (c) high surface energy and (d) low surface energy on the substrates.

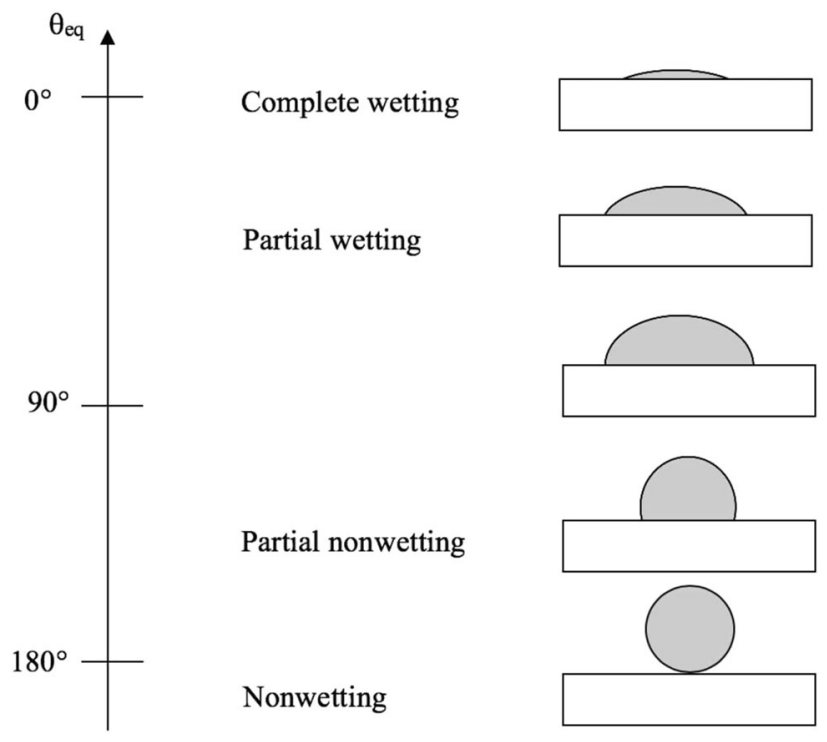

Fig. 17. Schematic of wetting behaviour of droplets onto substrate surface at different contact angle $\left(\theta_{\text {eq }}\right)$. single row of 16 nozzles of $21.5 \mu \mathrm{m}$ diameter spaced at $254 \mu \mathrm{m}$ with a typical drop diameter of $27 \mu \mathrm{m}$.

\section{CHALLENGES OF GRAPHENE-BASED INK}

Numerous studies of graphene-based inks have been reported in the past 10 years; however, more needs to be considered before they can be used in practical applications. Extensive work is required to produce large-scale, high-quality, low-cost and ecofriendly techniques for graphene-based ink. Ink formulation and properties such as viscosity, surface tension, contact angle, surface energy, etc. are the main influences on printing quality. The challenges can be divided into several areas: eco-friendly solvent, ink stability, graphene materials and substrate.

Most of the solvents used in the fabrication of graphene-based inks are not environmentally friendly and have high boiling points. The use of these common solvents, such as n-methylpyrrolidone (NMP) and dimethylformamide (DMF), limits the development of graphene-based ink technology. Thus, non-toxic and low-boiling-point solvents, 
Table V. Comparison of viscosity and surface tension of various types of conductive inks from literature

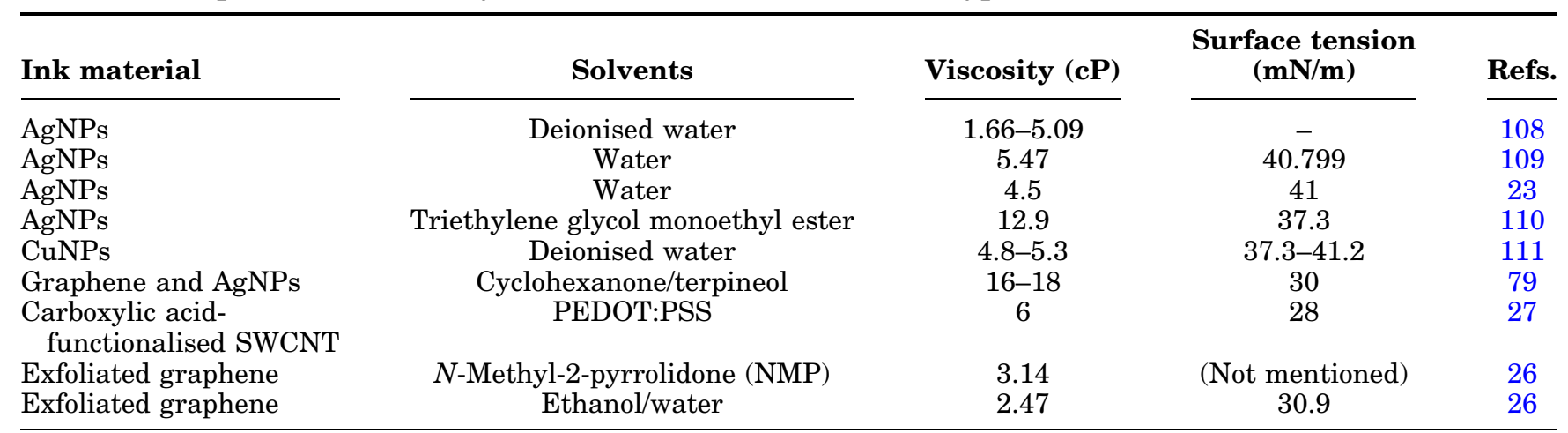

Table VI. Comparison of pros and cons of printing techniques for the fabrication of flexible electronics Printing
technique

Gravure Pr

Produce high-quality patterns in a cost-
effective manner

Use low-viscosity inks to prevent ink bleed-out from the gravure cells

Flexography A wide range of inks (solvent-based, waterbased, electron-beam curing inks, UV curing inks, etc.) can be printed

Uniform thin layers and better resolution than gravure

No strict physical requirements for the ink formulation

Screen Does not require high capital investment

printing

Aerosol jet High print resolution and applicable with various types of inks

Capable of printing inks with a wide range of viscosity $(1-1000 \mathrm{cP})$

The inks are atomised during printing to prevent aggregation

3D printing Can print any design and eco-friendly

Excess products are eliminated and no storage cost is required

Lower production costs

Spray coat- Low cost, time-saving, high repeatability, ing film deposition is easy to control and can produce film with thickness in nanometres

Can be scaled to large-area flexible substrates without specialised equipment

Inkjet print- Fine pattern generation, versatility, high ing repeatability, resolution and scalability Simple design and less waste of inks

Works without a physical printing mask that directly contacts the substrates

Economical and saves time compared to conventional printing technique

\section{$\frac{\text { Disadvantages }}{\text { Non-high resolution, e.g. less than } 20 \mu \mathrm{m}}$ \\ Inability to produce uniform structures with sharp edge pattern lines \\ Halo effect-the spreading of the ink outside the image areas due to the compression

$$
\text { applied }
$$ \\ An optimum range of width and thickness is required to decrease the ohmic losses and increase efficiency of the printed devices \\ Low-viscosity ink will simply run through the mesh}

The use of masks and waste of materials High wet thickness and exposure of the ink to atmosphere

Costly process which requires complex equipment

Refs.

$17,113,114$

$17,115,116$

$17,117,118$

Higher investment costs, lower production speed and not efficient for large series

Limited dimensions of product

Long process due to nozzle clogging

High air pressure for coating could damage the surface of the thin film

The coalescence of subsequently ejected ink droplets causes edges in a type of wave rather than a straight line

Nozzle clogging due to the aggregation of the particles in the dispersed solution 


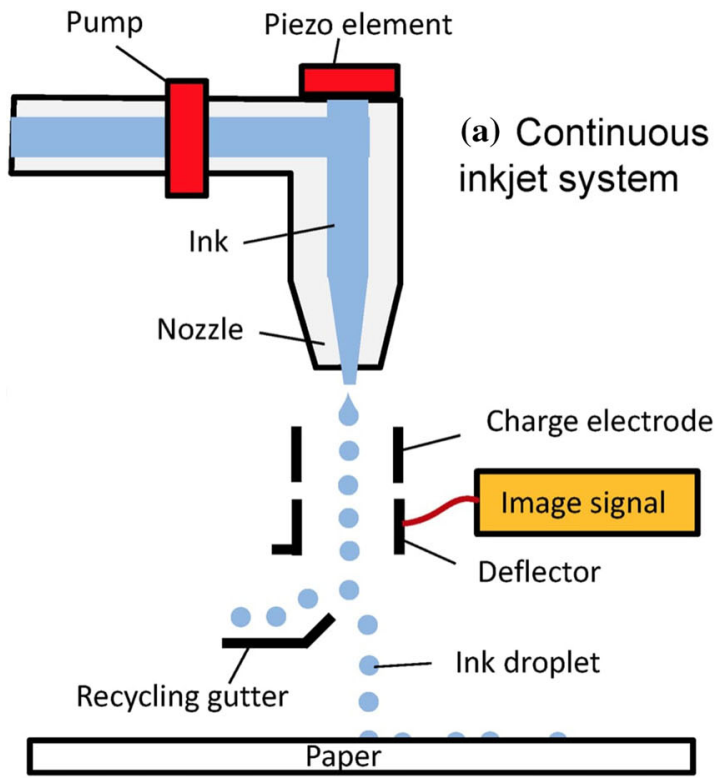

(b) On-demand inkjet system

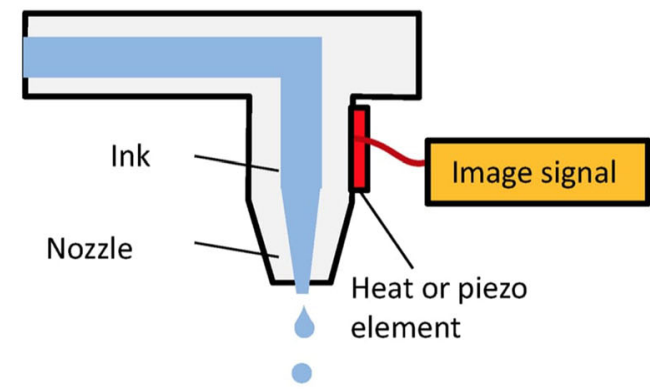

Ink droplet

\section{Paper}

Fig. 18. Schematic of inkjet printing: (a) continuous inkjet system and (b) on-demand inkjet system ${ }^{131}$ (reproduced with permission from MDPI, 2017).

Table VII. Comparison of drop-on-demand inkjet printing details from literature

\begin{tabular}{|c|c|c|c|}
\hline Type of ink & Type of inkjet printer & Cartridge details & Refs. \\
\hline Graphene & Fujifilm Dimatix 2800 printer & $2 \mathrm{~mL}$ of ink by syringe & 26 \\
\hline Graphene & Dimatix DMP 2800 system & DMC-11610 with 10 pL drop & 30 \\
\hline GO & Hewlett-Packard Deskjet K7108 & HP 853 by syringe & 31 \\
\hline Graphene & DMP2800 Dimatix Fujifilm & DMC-11610 with 10 pL drop & 33 \\
\hline GNPs & Dimatrix (DMP-2831) & DMC-11610 with 10 pL drop & 34 \\
\hline Graphene & Dimatix (DMP-2831) & DMC-11610 with 10 pL drop & 35 \\
\hline Graphene & Fujifilm Dimatix Materials Printer (DMP-2800) & DMC-11610 with 10 pL drop & 38 \\
\hline Graphene & Ceradrop X-Serie & DMC-11610 with $10 \mathrm{pL}$ drop & 39 \\
\hline rGO-Ag & Epson L301 commercial printer & $70 \mathrm{~mL}$ cartridge with $3 \mathrm{pL}$ droplets & 80 \\
\hline Graphene & Epson Stylus 1500 & S020049 & 132 \\
\hline
\end{tabular}

including water and alcohols, should be considered for the development of fully environmentally friendly graphene-based inks.

Ink properties such as viscosity, surface tension, contact angle and surface energy play vital roles in determining the print quality, and should be optimised to meet the specific printing requirements. A variety of surfactants, such as ionic, non-ionic and polymer stabilisers and bio-surfactants may be the preferred options to improve ink stability.

Most of the conductive inks reported in the literature are prepared using GO as the conductive filler. However, GO sheets are not electrically conductive. Post-treatment to reduce the oxygen content in GO is required; however, this process involves highly toxic materials which are not environmentally friendly. Because of that, pristine graphene is used for ink preparation, as this material has good electrical conductivity. However, pristine graphene still shows poor solubility in common solvents. By adding a suitable surfactant, the solubility of the conductive ink is reported to be improved without losing conductivity.

The high annealing temperatures of conductive ink inhibit its use for a wide range of substrates, thus limiting its application for flexible electronics. In addition, common plastic substrates have poor wettability, which will also influence the print quality. Therefore, surface treatment using ecofriendly solvents and techniques to improve the wettability of the substrate is still crucial.

\section{CONCLUSIONS}

In this report, we have reviewed the recent works on the types of graphene materials used in conductive ink, and the compositions and important properties of conductive inks. The pros and cons of graphene conductive ink have been compared with inks containing other common conductive nanomaterials. Clearly, graphene-based inks offer numerous advantages, including high electrical 
conductivity, compared to other common conductive nanomaterials. However, extensive studies are still required to consider eco-friendly solvents, ink stability, types of graphene materials and types of substrates. Therefore, major challenges still remain in preparing large-scale, high-quality, low-cost and eco-friendly techniques and handling for graphenebased ink. Graphene hybrid-based ink is an alternative way to improve the electrical properties of the conductive ink; however, this method involves high cost of raw materials, and optimisation of ink formulation is still necessary. We hope that this review will provide a good source of knowledge for researchers who are interested in graphene- and other conductive nanomaterial-based inks. Flexible electronics will be the next era of technology and hence we present this review as a stepping stone for the future.

\section{ACKNOWLEDGMENTS}

The authors acknowledge the financial support from the Ministry of Education Malaysia through the Fundamental Research Grant Scheme (FRGS MRSA; Grant No. 6071385). The authors gratefully acknowledge also the support from Universiti Sains Malaysia, the School of Materials \& Mineral Resources Engineering, Université de Lorraine, Campus France and National Centre for Scientific Research (CNRS). We were also grateful to Carbon Materials Group (E205)'s laboratory, Institut Jean Lamour, Université de Lorraine, France for the research attachment of the first author at Université de Lorraine, France.

\section{REFERENCES}

1. K.S. Novoselov, A.K. Geim, S.V. Morozov, D. Jiang, Y. Zhang, S.V. Dubonos, I.V. Grigorieva, and A.A. Firsov, Science 306, 666 (2004).

2. A. Bianco, H.M. Cheng, T. Enoki, Y. Gogotsi, R.H. Hurt, N. Koratkar, T. Kyotani, M. Monthioux, C.R. Park, J.M.D. Tascon, and J. Zhang, Carbon 65, 1 (2013).

3. A. Abdelghany, S.A. Elsherif, and H.T. Handal, Surf. Interfaces 9, 93 (2017).

4. S. Jaworski, E. Sawosz, M. Grodzik, A. Winnicka, M. Prasek, M. Wierzbicki, and A. Chwalibog, Int. J. Nanomedicine 8, 413 (2013).

5. D.A.C. Brownson and C.E. Banks, The Handbook of Graphene Electrochemistry (London: Springer, 2014).

6. P.R. Wallace, Phys. Rev. 71, 622 (1947).

7. G. Chen, W. Deng, D. Wu, C. Wu, J. Lu, P. Wang, and X. Chen, Carbon 42, 753 (2004).

8. M. Choucair, P. Thodarson, and J.A. Stride, Nat. Nanotechnol. 4, 30 (2009).

9. K.S. Novoselov, V.I. Fal'ko, L. Colombo, P.R. Gellert, M.G. Schwab, and K. Kim, Nature 490, 192 (2012).

10. C.T.J. Low, F.C. Walsh, M.H. Chakrabarti, M.A. Hashim, and M.A. Hussain, Carbon 54, 1 (2013).

11. L. Speyer, S. Fontana, S. Cahen, J. Ghanbaja, G. Medjahdi, and C. Hérold, Solid State Sci. 50, 42 (2015).

12. W. Cui, W. Lu, Y. Zhang, G. Lin, T. Wei, and L. Jiang, Colloids Surf. A Physicochem. Eng. Asp. 358, 35 (2010).

13. X. Nie, H. Wang, and J. Zou, Appl. Surf. Sci. 261, 554 (2012).

14. J. Kastner, T. Faury, H.M. Außerhuber, T. Obermüller, H. Leichtfried, M.J. Haslinger, E. Liftinger, J. Innerlohinger,
I. Gnatiuk, D. Holzinger, and T. Lederer, Microelectron. Eng. 176, 84 (2017).

15. J.S. Kang, H.S. Kim, J. Ryu, H.T. Hahn, S. Jang, and J.W. Joung, J. Mater. Sci. Mater. Electron. 21, 1213 (2010).

16. N. Perinka, C.H. Kim, M. Kaplanova, and Y. Bonnassieux, Phys. Proc. 44, 120 (2013).

17. S. Khan, L. Lorenzelli, and R.S. Dahiya, IEEE Sens. J. 15, 3164 (2015).

18. S.D. Hoath, Fundamentals Of Inkjet Printing (Weinheim: Wiley-VCH, 2016).

19. W. Yang and C. Wang, J. Mater. Chem. C 4, 7193 (2016).

20. R. Banfield, Specialist printing worldwide: issue one (2013), https://www.appliedinksolutions.com/pdf/sp1134043.pdf. Accessed October 2018.

21. D.A. Roberson, R.B. Wicker, L.E. Murr, K. Church, and E. Macdonald, Materials (Basel) 4, 963 (2011).

22. H.W. Choi, T. Zhou, M. Singh, and G.E. Jabbour, Nanoscale 7, 3338 (2015).

23. L. Liu, X. Wan, L. Sun, S. Yang, Z. Dai, Q. Tian, M. Lei, X. Xiao, C. Jiang, and W. Wu, RSC Adv. 5, 9783 (2015).

24. M. Stoppa and A. Chiolerio, Sensors (Basel) 14, 11957 (2014).

25. H. Zervos, Printed electronics market update-opportunities for the printing industry, http://www.inprintshow.com/ usa/conference/pdf/Harry-Zervos.pdf. Accessed September 2018.

26. A. Capasso, A.E. Del Rio Castillo, H. Sun, A. Ansaldo, V. Pellegrini, and F. Bonaccorso, Solid State Commun. 224, $53(2015)$

27. A. Denneulin, J. Bras, F. Carcone, C. Neuman, and A. Blayo, Carbon 49, 2603 (2011).

28. A. Kamyshny and S. Magdassi, Small 10, 3515 (2014).

29. Y. Li, D. Lu, and C.P. Wong, Electrical Conductive Adhesives with Nanotechnologies (New York: Springer, 2010).

30. K. Arapov, R. Abbel, G. de With, and H. Friedrich, Faraday Discuss. 173, 323 (2014).

31. L. Huang, Y. Huang, J. Liang, X. Wan, and Y. Chen, Nano Res. 4, 675 (2011).

32. L. Pei and Y.F. Li, RSC Adv. 7, 51711 (2017).

33. Y. Gao, W. Shi, W. Wang, Y. Leng, and Y. Zhao, Ind. Eng. Chem. Res. 53, 16777 (2014).

34. F. Miao, S. Majee, M. Songa, J. Zhao, S.L. Zhang, and Z.B. Zhang, Synth. Met. 220, 318 (2016).

35. S. Majee, C. Liu, B. Wu, S.L. Zhang, and Z.B. Zhang, Carbon 114, 77 (2017).

36. P. He and B. Derby, 2D Mater. 4, 021021 (2017).

37. Y. Su, J. Du, D. Sun, C. Liu, and H. Cheng, Nano Res. 6, 842 (2013).

38. E.B. Secor, P.L. Prabhumirashi, K. Puntambekar, M.L. Geier, and M.C. Hersam, J. Phys. Chem. Lett. 4, 1347 (2013).

39. E.B. Secor, B.Y. Ahn, T.Z. Gao, J.A. Lewis, and M.C. Hersam, Adv. Mater. 27, 6683 (2015).

40. E.B. Secor, T.Z. Gao, A.E. Islam, R. Rao, S.G. Wallace, J. Zhu, K.W. Putz, B. Maruyama, and M.C. Hersam, Chem. Mater. 29, 2332 (2017).

41. A. Iwakoshi, T. Nanke, and T. Kobayashi, Gold Bull. 38, 107 (2005).

42. C. Schoner, A. Tuchscherer, T. Blaudeck, S.F. Jahn, R.R. Baumann, and H. Lang, Thin Solid Films 531, 147 (2013).

43. K. Rajan, I. Roppolo, A. Chiappone, S. Bocchini, D. Perrone, and A. Chiolerio, Nanotechnol. Sci. Appl. 9, 1 (2016)

44. A. Kamyshny, M. Ben-Moshe, S. Aviezer, and S. Magdassi, Macromol. Rapid Commun. 26, 281 (2005).

45. I. Kim, T.M. Lee, and J. Kim, J. Alloy. Compd. 596, 158 (2014).

46. X. Zhou, W. Li, M. Wu, S. Tang, and D. Liu, Appl. Surf. Sci. 292, 537 (2014).

47. Z. Zhang and W. Zhu, J. Alloy. Compd. 649, 687 (2015).

48. D.G. Lee, D.K. Kim, Y.J. Moon, and S.J. Moon, Thin Solid Films 546, 443 (2013).

49. S. Vunnam, K. Ankireddy, J. Kellar, and W. Cross, Thin Solid Films 531, 294 (2013). 
50. B.J. de Gans, P.C. Duineveld, and U.S. Schubert, Adv. Mater. 16, 203 (2004).

51. C.Y. Tsai, W.C. Chang, G.L. Chen, C.H. Chung, J.X. Liang, W.Y. Ma, and T.N. Yang, Nanoscale Res. Lett. 10, 357 (2015).

52. Y.T. Kwon, Y.I. Lee, S. Kim, K.J. Lee, and Y.H. Choa, Appl. Surf. Sci. 396, 1239 (2017).

53. W. Xu, X. Dai, T. Zhang, and T. Wang, Chem. Eng. Sci. 190, $40(2018)$

54. Y. Lee, J.R. Choi, K.J. Lee, N.E. Stott, and D. Kim, Nanotechnology 19, 415604 (2008).

55. M. Berkei, Conductive coatings using carbon nanotubes: a fascinating material for the coating producer's toolbox. (CHEManager, Europe, 2011).

56. P. Mukhopadhyay and R.K. Gupta, Graphite, Graphene, and Their Polymer Nanocomposites, 1st ed. (Boca Raton: CRC Press, 2013).

57. K. Kordás, T. Mustonen, G. Tóth, H. Jantunen, M. Lajunen, C. Soldano, S. Talapatra, S. Kar, R. Vajtai, and P.M. Ajayan, Small 2, 1021 (2006).

58. W. Zhou, A.B. Belay, K. Davis, N.S. Hickman, in 38th IEEE Photovoltaic Specialists Conference, vol. 2324 (2012).

59. Y. Sabba and E.L. Thomas, Macromolecules 37, 4815 (2004).

60. D.M. Kernan and W.J. Blau, Europhys. Lett. 83, 66009 (2008).

61. E. Song, R.P. Tortorich, T.H. da Costa, and J.W. Choi, Microelectron. Eng. 145, 143 (2015)

62. M.V. Kulkarni, S.K. Apte, S.D. Naik, J.D. Ambekar, and B.B. Kale, Sens. Actuators B Chem. 178, 140 (2013).

63. Z. Stempien, T. Rybicki, E. Rybicki, M. Kozanecki, and M.I. Szynkowska, Synth. Met. 202, 49 (2015).

64. J.B. Schlenoff and H. Xu, J. Electrochem. Soc. 139, 2397 (1992).

65. H.S. Abdulla and A.I. Abbo, Int. J. Electrochem. Sci. 7, 10666 (2012).

66. A.A.A. Almario and R.L.T. Caceres, J. Chil. Chem. Soc. 54, $14(2009)$

67. S.A. Popli and U.D. Patel, J. Electrochem. Sci. Eng. 5, 145 (2015).

68. Y. Hong, J. Kanicki, and I.E.E.E. Trans, Electron. Dev. 51, $1562(2004)$

69. J. Ha, J. Park, J. Ha, D. Kim, S. Chung, C. Lee, and Y. Hong, Org. Electron. 19, 147 (2015).

70. M.T. Sharbati, Graphene quantum dot-based organic light emitting diodes, Master's Thesis, University of Pittsburgh, 2016.

71. L. Groenendaal, F. Jonas, D. Freitag, H. Pielartzik, and J.R. Reynolds, Adv. Mater. 12, 481 (2000).

72. Y.H. Kim, C. Sachse, M.L. Machala, C. May, L. MüllerMeskamp, and K. Leo, Adv. Funct. Mater. 21, 1076 (2011).

73. H. Abroshan, H. Akbarzadeh, F. Taherkhani, and G. Parsafar, Mol. Phys. 109, 709 (2011).

74. J. Cho, K.H. Shin, and J. Jang, Thin Solid Films 518, 5066 (2010).

75. J. Chang, J. He, D. Li, and A.C.S. Appl, Mater. Interfaces 10, 19116 (2018).

76. Y. Xu, I. Hennig, D. Freyberg, A.J. Strudwick, M.G. Schwab, T. Weitz, and K.C.P. Cha, J. Power Sources 248, 483 (2014).

77. D. Li, J. Huang, and R.B. Kaner, Acc. Chem. Res. 42, 135 (2009).

78. W. Yang, C. Wang, V. Arrighi, and F. Vilela, J. Mater. Sci. Mater. Electron. 28, 8218 (2017).

79. D. Deng, S. Feng, M. Shi, and C. Huang, J. Mater. Sci. Mater. Electron. 28, 15411 (2017).

80. W. Zhang, E. Bi, M. Li, and L. Gao, Colloids Surf. A Physicochem. Eng. Asp. 490, 232 (2016).

81. L. Li, M. Gao, Y. Guo, J. Sun, Y. Li, F. Li, Y. Song, and Y. Li, J. Mater. Chem. C 5, 2800 (2017).

82. A. Ji, Y. Chen, X. Wang, and C. Xu, J. Mater. Sci. Mater. Electron. 29, 13032 (2018)

83. R. Zhang, B. Peng, and Y. Yuan, Compos. Sci. Technol. 168 , 118 (2018).
84. E. Jewell, S. Hamblyn, T. Claypole, and D. Gethin, Coatings 5, 172 (2015).

85. T.S. Tran, N.K. Dutta, and N.R. Choudhury, Adv. Colloid Interface Sci. 261, 41 (2018).

86. W. Shen, X. Zhang, Q. Huang, Q. Xu, and W. Song, Nanoscale 6, 1622 (2014).

87. W. Zapka, Handbook of Industrial Inkjet Printing: A Full System Approach (Weinheim: Wiley-VCH, 2018).

88. E. Svanholm, Printability and ink-coating interactions in inkjet printing, Dissertation, Karlstad University Studies, 2007.

89. Y.L. Tai and Z.G. Yang, Surf. Interface Anal. 44, 529 (2012).

90. R. Dang, L. Song, W. Dong, C. Li, X. Zhang, G. Wang, and X. Chen, ACS Appl. Mater. Interfaces 6, 622 (2014).

91. T. Martin, SGIA J. 3, 5 (2005).

92. A.J. Kell, C. Paquet, O. Mozenson, I. Djavani-Tabrizi, B. Deore, X. Liu, G.P. Lopinski, R. James, K. Hettak, J. Shaker, A. Momciu, J. Ferrigno, O. Ferrand, J.X. Hu, S. Lafreniere, and P.R.L. Malenfant, ACS Appl. Mater. Interfaces 9, 17226 (2017).

93. Y. Zhang, P. Zhu, G. Li, T. Zhao, X. Fu, R. Sun, F. Zhou, and C.P. Wong, ACS Appl. Mater. Interfaces 6, 560 (2014).

94. H.J. Hwang, K.H. Oh, and H.S. Kim, Sci. Rep. 6, 19696 (2016).

95. S. Magdassi, The Chemistry of Inkjet Inks (Singapore: World Scientific Publishing Company, 2010).

96. M.C. Dang, T.M.D. Dang, and E. Fribourg-Blanc, Adv. Nat. Sci. Nanosci. Nanotechnol. 4, 015009 (2013).

97. A.I. Titkov, O.G. Bukhanets, R.M. Gadirov, Y.M. Yukhin, and N.Z. Lyakhov, Inorg. Mater. Appl. Res. 6, 375 (2015).

98. M.J. Large, S.P. Ogilvie, M. Meloni, A. Amorim Graf, G. Fratta, J. Salvage, A.A.K. King, and A.B. Dalton, Nanoscale 10, 1582 (2018).

99. V. Chovancova, A. Pekarovicova, P.D. Fleming, in Proceedings of the Society For Imaging Science And Technology, vol. 143 (2005).

100. D.S. Viswanath, T. Ghosh, D.H.L. Prasad, N.V.K. Dutt, and K.Y. Rani, Visocsity of Liquids (Dordrecht: Springer, 2007).

101. L. Dybowska-Sarapuk, K. Kielbasinski, A. Arazna, K. Futera, A. Skalski, D. Janczak, M. Sloma, and M. Jakubowska, Nanomaterials 8, 602 (2018).

102. P. Ihalainen, A. Määttänen, and N. Sandler, Int. J. Pharm. 494, 585 (2015).

103. D.J. Shaw, Introduction to Colloid and Surface Chemistry, 4th ed. (Oxford: Butterworth-Heinemann, 1996).

104. K. Woo, D. Jang, Y. Kim, and J. Moon, Ceram. Int. 39, 7015 (2013).

105. M. Michel, J.A. Desai, C. Biswas, and A.B. Kaul, Nanotechnology 27, 1 (2016).

106. G. Cummins and M.P.Y. Desmulliez, Circuit Word 38, 193 (2012).

107. P. Li, C.A. Tao, B. Wang, J. Huang, T. Li, and J. Wang, J. Nanosci. Nanotechnol. 18, 713 (2018).

108. J.T. Wu, S.L.C. Hsu, M.H. Tsai, and W.S. Hwang, Thin Solid Films 517, 5913 (2009).

109. M. Vaseem, K.M. Lee, A.R. Hong, Y.B. Hahn, and A.C.S. Appl, Mater. Interfaces 4, 3300 (2012).

110. T. Öhlund, J. Örtegren, S. Forsberg, and H.E. Nilsson, Appl. Surf. Sci. 259, 731 (2012).

111. S. Jeong, H.C. Song, W.W. Lee, S.S. Lee, Y. Choi, W. Son, E.D. Kim, C.H. Paik, S.H. Oh, and B.H. Ryu, Langmuir 27, 3144 (2011)

112. I.C. Cheng and S. Wagner, Overview of Flexible Electronics Technology (Boston: Springer, 2009).

113. D.A. Clark, Major trends in gravure printed electronics, BS thesis, California Polytechnic State University, 2010.

114. J. Yang, D. Vak, N. Clark, J. Subbiah, W.W.H. Wong, D.J. Jones, S.E. Watkins, and G. Wilson, Solar Energy Mater. Sol. Cells 109, 47 (2013).

115. R.R. Søndergaard, M. Hösel, and F.C. Krebs, J. Polym. Sci. Part B Polym. Phys. 51, 16 (2013). 
116. J. Siden, H.E. Nilsson, in International Symposium on Antennas and Propagation Society, vol. 1745 (2007).

117. P.F. Moonen, I. Yakimets, and J. Huskens, Adv. Mater. 24, 5526 (2012)

118. F.C. Krebs, M. Jørgensen, K. Norrman, O. Hagemann, J. Alstrup, T.D. Nielsen, J. Fyenbo, K. Larsen, and J. Kristensen, Solar Energy Mater. Sol. Cells 93, 422 (2009).

119. A. Mahajan, C.D. Frisbie, L.F. Francis, and A.C.S. Appl, Mater. Interfaces 5, 4856 (2013).

120. E. Jabari and E. Toyserkani, Carbon 91, 321 (2015).

121. T. Seifert, E. Sowade, F. Roscher, M. Wiemer, T. Gessner, and R.R. Baumann, Ind. Eng. Chem. Res. 54, 769 (2015).

122. L. Kubáč and O. Kodym, MATEC Web Conf. 134, 00027 (2017).

123. Y. Zheng, S. Li, W. Shi, and J. Yu, Nanoscale Res. Lett. 9, 145 (2014).

124. M. Eslamian, Coatings 4, 60 (2014).

125. P. Calvert, Chem. Mater. 13, 3299 (2001).

126. Y. Aleeva and B. Pignataro, J. Mater. Chem. C 2, 6436 (2014).
127. M. Singh, H.M. Haverinen, P. Dhagat, and G.E. Jabbour, Adv. Mater. 22, 673 (2010).

128. P. Mariani, L. Vesce, and A. Di Carlo, Semicond. Sci. Technol. 30, 104003 (2015).

129. H.P. Le, J. Imaging Sci. Technol. 42, 49 (1998).

130. D. Wallace, D. Hayes, T. Chen, V. Shah, D. Radulescu, P. Cooley, K. Wachtler, A. Nallani, in Proceedings of the First International Conference on Integration and Commercialization of Micro and Nanosystems, China, vol. 1161 (2007).

131. G.K. Lau and M. Shrestha, Micromachines 8, 194 (2017).

132. F. Torrisi, T. Hasan, W. Wu, Z. Sun, A. Lombardo, T.S. Kulmala, G.W. Hsieh, S. Jung, F. Bonaccorso, P.J. Paul, D. Chu, and A.C. Ferrari, ACS Nano. 6, 2992 (2012).

133. N. Karim, S. Afroj, A. Malandraki, S. Butterworth, C. Beach, M. Rigout, K.S. Novoselov, A.J. Casson, and S.G. Yeates, J. Mater. Chem. C 5, 11640 (2017).

Publisher's Note Springer Nature remains neutral with regard to jurisdictional claims in published maps and institutional affiliations. 